\title{
Retrofitting unreinforced masonry by steel fiber reinforced mortar coating: uniaxial and diagonal compression tests
}

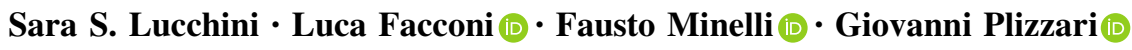

Received: 14 April 2020/ Accepted: 30 October 2020/Published online: 25 November 2020

(C) The Author(s) 2020

\begin{abstract}
Thin layers of mortar reinforced with steel fibers can be applied on one or both sides of bearing walls as an effective seismic strengthening of existing masonry buildings. To assess the effectiveness of this technique, an experimental study on masonry subassemblages was carried out at the University of Brescia. This paper summarizes and discusses the main results of the investigation, which included mechanical characterization tests on masonry and its components as well as on the Steel Fiber Reinforced Mortar (SFRM) used to retrofit the masonry samples. Uniaxial and diagonal compression tests were carried out on both unstrengthened wallets and masonry samples retrofitted with $25 \mathrm{~mm}$ thick SFRM coating. Both single-sided and double-sided retrofitting configurations for application on wall surfaces were considered. The results highlighted the ability of the technique to improve the compressive and the shear behavior of masonry, even in case of single-sided
\end{abstract}

S. S. Lucchini · L. Facconi · F. Minelli $(\bowtie)$ · G. Plizzari Department of Civil, Architectural, Environmental Engineering and of Mathematics (DICATAM), University of Brescia, Brescia, Italy

e-mail: fausto.minelli@unibs.it

S. S. Lucchini

e-mail: s.lucchini002@unibs.it

L. Facconi

e-mail: luca.facconi@unibs.it

G. Plizzari

e-mail: giovanni.plizzari@unibs.it strengthening. Moreover, no premature debonding of coating was observed. Lastly, the manuscript presents the results of a numerical investigation that was performed both to simulate the diagonal compression tests described in the first part of the paper and to predict the response of panels with different strengthening configurations.

Keywords Masonry · Hollow clay units · Retrofitting · Coating - Steel fiber reinforced mortar . Compressive strength $\cdot$ Shear strength $\cdot$ Numerical analysis

\section{Introduction}

Unreinforced Masonry (URM) has been used for constructing a large number of buildings placed in seismic areas worldwide. The typical low tensile strength of URM makes existing buildings vulnerable to both in-plane and out-of-plane seismic actions $[1,2]$. Thus, retrofitting interventions are frequently required to enhance masonry resistance and achieve the seismic safety level required by structural codes [3-5].

Many different technologies have been developed for strengthening and rehabilitating URM buildings. The traditional methods include surface treatments (i.e. shotcrete [6, 7], ferrocement, reinforced mortar 
coating [8]), prestressing with steel bars/ties and grout injections [9]. Besides these methods, other technologies have been recently developed by adopting advanced materials such as externally bonded fiberreinforced polymers (FRP), near-surface mounted FRP rebars and surface coatings reinforced with polymer-based grid reinforcement [10-15].

An alternative technique that combines the advantages of traditional methods with the use of advanced materials is represented by Steel Fiber Reinforced Mortar (SFRM) coating. This rather new retrofitting method consists of a thin mortar coating, bonded either on one or both sides of masonry elements and reinforced with short fibers (i.e. having length, in general, shorter that the coating thickness) randomly distributed in the mortar matrix. In addition to the time-saving related to the substitution of conventional rebars (whose placing is time consuming), steel fibers allow constructing thin coatings (e.g. 20-30 mm thick) since minimum rebar cover recommendations to fulfill durability are no longer required. Moreover, the improved tensile toughness provided by fibers to mortar leads to a better crack control in service loading conditions.

The effectiveness of this technique for masonry has been proved by few studies [16] including those [17] carried out by the authors through in-plane cyclic tests on full scale solid and hollow clay blocks walls strengthened with $25 \mathrm{~mm}$ thick SFRM coatings.

This study is part of a comprehensive experimental and numerical research that aims at investigating the use of SFRM coating for seismic retrofitting of masonry buildings. In addition to the traditional retrofitting scheme based on the application of coating on both sides of the wall, the research suggests the use of single-sided retrofitting as an alternative strengthening method. Especially in case the retrofitting intervention involves only the perimeters walls of the building, the use of a single layer of coating applied to the façade allows to minimize disturbances and interruption of normal functionality.

The results discussed in this work concern the tests carried out to characterize the materials used to construct a full-scale masonry building (plan dim. $5.75 \times 4.25 \mathrm{~m}$, height $6.7 \mathrm{~m}$ ) tested at the University of Brescia (Italy) under cyclic loading [18]. The building was retrofitted with a $30 \mathrm{~mm}$ thick layer of SFRM applied only on the external surfaces of the perimeter bearing walls. The results of the test on the building will be fully described elsewhere. Here, the data obtained from mechanical tests performed on masonry (i.e. uniaxial compression tests, diagonal compression tests) and its components (i.e. compression strength of unit and mortar, flexural strength of mortar) will be presented together with the results of SFRM characterization. The latter include free-shrinkage linear tests, uniaxial compression tests and flexural tests carried out according to $f i b$ Model Code 2010 (MC2010) [19] to determine the tensile behavior of mortar after cracking.

Particular attention will be paid to the discussion of the results provided by the diagonal compression tests. Therefore, an entire section of the paper will be devoted to the numerical simulation of the diagonal tests to get a full understanding of the experimental results.

\section{Characterization of masonry components}

The present section reports the results of the tests performed to determine the mechanical behavior of the masonry components. Hollow clay units and mortar samples were collected during the construction of the masonry wallets and panels, which were tested under uniaxial and diagonal compression loading, respectively. To better represent the properties of masonry used to construct the full scale building mentioned above, all the samples were stored outdoor to reproduce the same ambient conditions of the building.

The mean values of mechanical properties resulting from the tests as well as the number of collected samples are reported in Table 1. As the masonry wallets and panels were not built at the same time, the mortar materials used for their construction were characterized separately. Therefore, a column of Table 1, named as "Source of samples", described the type of masonry specimen from which each component was collected.

\subsection{Unit properties}

The $250 \times 200 \times 190 \mathrm{~mm}^{3}$ hollow clay units selected for this study are characterized by a percentage of voids of $60 \%$, a weight of about $6.1 \mathrm{~kg}$ and a density of $640 \mathrm{~kg} / \mathrm{m}^{3}$. That percentage of voids was chosen to represent clay unit typologies widely used 
Table 1 Mechanical properties of masonry components

\begin{tabular}{|c|c|c|c|c|}
\hline $\begin{array}{l}\text { Masonry } \\
\text { component }\end{array}$ & Source of samples & Property & $\begin{array}{l}\text { Number of } \\
\text { samples }\end{array}$ & $\begin{array}{l}\text { Mean value } \\
(\mathrm{MPa})\end{array}$ \\
\hline \multirow[t]{2}{*}{ Hollow unit } & \multirow[t]{2}{*}{$\begin{array}{l}\text { Masonry wallets for uniaxial } \\
\text { compression test }\end{array}$} & $\begin{array}{l}\text { Compressive strength parallel to } \\
\text { holes }\end{array}$ & 3 & $\begin{array}{l}13.44 \\
\quad(\mathrm{CoV}=4.7 \%)\end{array}$ \\
\hline & & $\begin{array}{l}\text { Compressive strength } \\
\text { perpendicular to holes }\end{array}$ & 3 & $\begin{array}{l}2.28 \\
\quad(\mathrm{CoV}=19.6 \%)\end{array}$ \\
\hline \multirow[t]{5}{*}{$\begin{array}{l}\text { Mortar for masonry } \\
\text { joints }\end{array}$} & $\begin{array}{l}\text { Masonry wallets for uniaxial } \\
\text { compression test }\end{array}$ & Flexural tensile strength & 12 & $\begin{array}{l}2.66 \\
(\mathrm{CoV}=9.9 \%)\end{array}$ \\
\hline & $\begin{array}{l}\text { Masonry panels for diagonal } \\
\text { compression test }\end{array}$ & Flexural tensile strength & 9 & $\begin{array}{l}2.68 \\
\quad(\mathrm{CoV}=11.0 \%)\end{array}$ \\
\hline & $\begin{array}{l}\text { Masonry wallets for uniaxial } \\
\text { compression test }\end{array}$ & Compressive strength & 24 & $\begin{array}{l}6.91 \\
\quad(\mathrm{CoV}=11.6 \%)\end{array}$ \\
\hline & $\begin{array}{l}\text { Masonry panels for diagonal } \\
\text { compression test }\end{array}$ & Compressive strength & 18 & $\begin{array}{l}7.42 \\
\quad(\mathrm{CoV}=10.5 \%)\end{array}$ \\
\hline & Additional complementary test & Elastic modulus & 16 & $\begin{array}{l}6200 \\
\quad(\mathrm{CoV}=9.00 \%)\end{array}$ \\
\hline
\end{tabular}

for buildings in Northern Italy from late ' $60 \mathrm{~s}$ to' $80 \mathrm{~s}$ of the last century.

The compressive strength of units was determined according EN 772-1 [20]. The loaded surfaces of each block were capped to obtain a smooth flat surface. A total of six units were tested, three of which parallel and the remaining three perpendicular to the direction of the holes. The mean values of the compressive strength are summarized in Table 1 together with the corresponding Coefficient of Variation $(\mathrm{CoV})$.

\subsection{Properties of mortar for masonry joints}

To simulate typical properties of existing masonry buildings, bed and head joints were filled with a readymix cement-based mortar (cement:hydraulic lime:sand $-1: 2: 9$ by volume) complying with the strength class M5 according EN 998-2 [21]. The mean flexural and cubic compressive strength were determined according EN 1015-11 [22] by testing a total of twelve and nine prismatic specimens having dimensions $40 \times 40 \times 160 \mathrm{~mm}^{3}$ and $40 \times 40 \times 40 \mathrm{~mm}^{3}$, respectively. Sixteen cylinders with a diameter of $80 \mathrm{~mm}$ and a length of $250 \mathrm{~mm}$ were cast separately and then tested according to UNI EN 12390-13 [23] to determine the secant elastic modulus of the mortar. The test results are summarized in Table 1 . Note that all the mortar samples were stored for a minimum of 28 days prior testing.

\section{Characterization of sfrm}

A series of tests were carried out to characterize the main mechanical properties as well as the free shrinkage behavior of SFRM used to retrofit unreinforced masonry.

The SFRM was obtained by mixing $24 \%$ (in weight) of water with a commercial ready-mix cement-based mortar containing $60 \mathrm{~kg} / \mathrm{m}^{3}(0.76 \%$ by volume) of double hooked-end steel fibers having a length of $32 \mathrm{~mm}$, a diameter of $0.4 \mathrm{~mm}$ and a tensile strength of $2800 \mathrm{MPa}$. The density of fresh mortar was approximately equal to $2140 \mathrm{~kg} / \mathrm{m}^{3}$.

The tests performed according UNI EN 1015-11 [22] on twelve prismatic beams $\left(40 \times 40 \times 160 \mathrm{~mm}^{3}\right)$ provided a mean compressive cube strength and a flexural strength respectively equal to $36.4 \mathrm{MPa}(\mathrm{CoV}=1.8 \%)$ and $6.8 \mathrm{MPa}$ $(\mathrm{CoV}=14.5 \%)$. A mean secant Young's modulus of $20,430 \mathrm{MPa}(\mathrm{CoV}=8.4 \%)$ was obtained from the uniaxial compression tests on three cylinders (diameter $=80 \mathrm{~mm}$; length $=210 \mathrm{~mm}$ ) carried out according UNI EN 12390-13 [23].

To determine the tensile behavior of SFRM after cracking, three-point bending tests (3PBTs) on five notched specimens (dimensions: $40 \times 150 \times 600 \mathrm{~mm}^{3}$ ) were performed according UNI EN 14651 [24]. The beams had a height of $150 \mathrm{~mm}$, a span length of $500 \mathrm{~mm}$ and a notch depth 
of $25 \mathrm{~mm}$ (Fig. 1a). The reduced width of the specimens $(40 \mathrm{~mm}$ rather than $150 \mathrm{~mm}$, as required by this standard) was chosen to better represent the typical field application of this material and its fracture behavior, which is governed by the $2 \mathrm{D}$ orientation of fibers. The limit of proportionality $\mathrm{f}_{\mathrm{L}, \mathrm{m}}=5.1 \mathrm{MPa}$ $(\mathrm{CoV}=10.5 \%)$ and the residual flexural strengths $\mathrm{f}_{\mathrm{R}, 1 \mathrm{~m}}=8.2 \mathrm{MPa} \quad(\mathrm{CoV}=15.3 \%), \mathrm{f}_{\mathrm{R}, 2 \mathrm{~m}}=9.1 \mathrm{MPa}$ $(\mathrm{CoV}=15.9 \%), \quad \mathrm{f}_{\mathrm{R}, 3 \mathrm{~m}}=8.7 \mathrm{MPa} \quad(\mathrm{CoV}=17.7 \%)$, $\mathrm{f}_{\mathrm{R}, 4 \mathrm{~m}}=7.8 \mathrm{MPa} \quad(\mathrm{CoV}=15.6 \%), \quad$ corresponding respectively to CMOD (Crack Mouth Opening Displacements) values of $0.5 \mathrm{~mm}, 1.5 \mathrm{~mm}, 2.5 \mathrm{~mm}$ and $3.5 \mathrm{~mm}$, were determined according to MC2010 [19]. As shown by the nominal tensile stress-CMOD curves of Fig. 1b, the SFRM was characterized by hardening behavior after cracking, with high values of the post-cracking tensile strength and toughness. The latter can be quantified by the mode-I tensile fracture energy $\left(G_{f}^{I}\right)$ [25] represented by the area subtending the post-cracking uniaxial stress $\left(\mathrm{f}_{1}\right)$ - crack width (w) law of the material (Fig. 9). As will be discussed in Sect. 6 , the $\mathrm{f}_{1}$-w law was obtained from the numerical back analysis of the 3PBTs, which provided the bestfitting curve depicted in Fig. 1b. As shown in Table 4, the fracture energy of the SFRM (i.e., $G_{f}^{I}=10.3 \mathrm{~N} /$

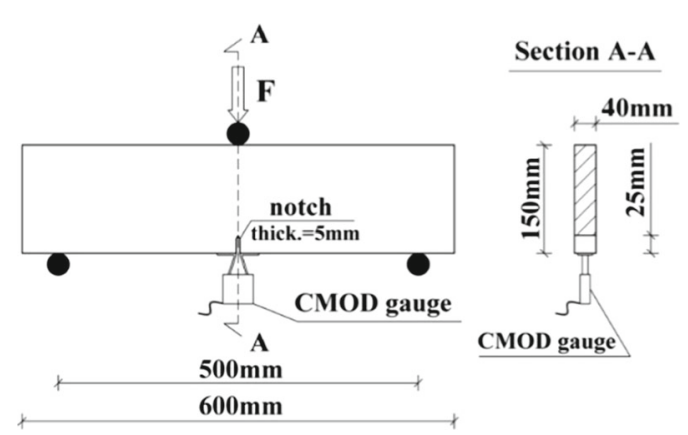

(a) $\mathrm{mm}$ ) was quite higher than that (e.g., $G_{f}^{I}=3-6 \mathrm{~N} / \mathrm{mm}$ $[19,26,27])$ typically exhibited by normal strength concrete containing similar amounts steel fibers.

The free drying shrinkage of the mortar matrix was monitored according to UNI 11307 [28] by testing three prismatic beams having dimensions $76 \times 76 \times 285 \mathrm{~mm}^{3}$. After 1 day wet- curing, the specimens were stored at constant temperature $\left(20{ }^{\circ} \mathrm{C}\right)$ and relative humidity $(50 \%)$ while monitoring drying shrinkage at different times for a minimum of 90 days. A mechanical dial comparator with a resolution of $0.001 \mathrm{~mm}$ was adopted to measure the axial deformation of the samples. The data obtained from measurements showed that the drying shrinkage strains detected at 30,60 and 90 days were respectively equal to $372 \times 10^{-6}, 559 \times 10^{-6}$ and $592 \times 10^{-6}$. After 90 days from casting, the increment of drying shrinkage became negligible.

\section{Uniaxial compression test on masonry wallets}

\subsection{Test method}

The $250 \times 200 \times 190 \mathrm{~mm}^{3}$ hollow clay units and the cement-based mortar described above were the basic

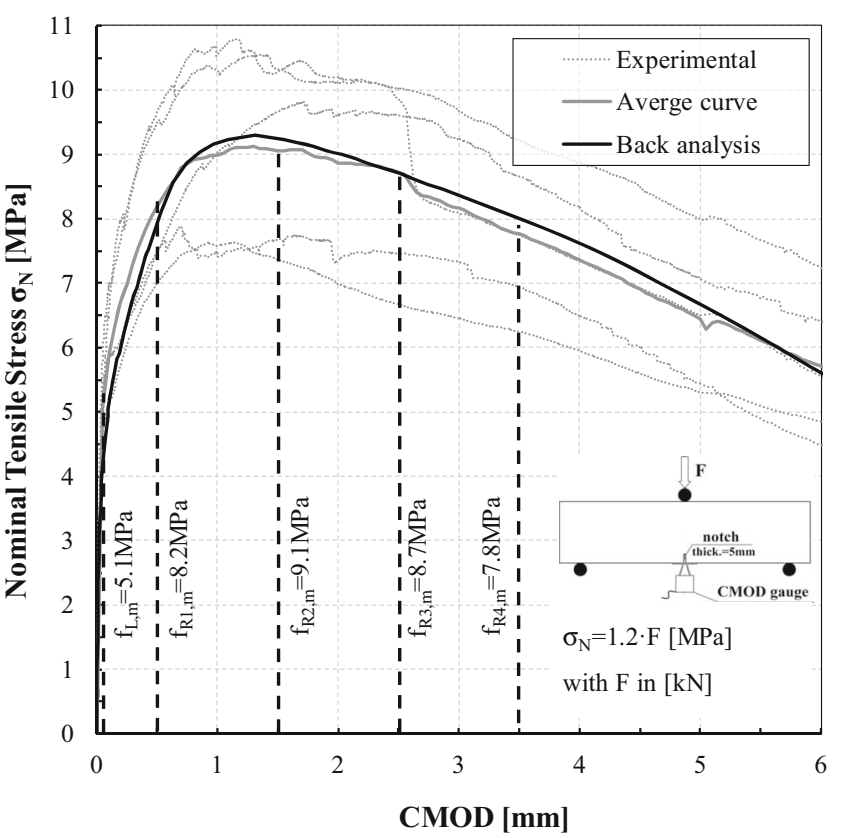

(b)

Fig. 1 3PBT on SFRM notched beams: loading set-up (a); experimental vs numerical Nominal stress-CMOD curves (b)

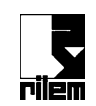


components of masonry used in this research. The head and bed joints had a nominal thickness of $10 \mathrm{~mm}$ and were both filled with mortar. The resulting masonry had an average density of about $745 \mathrm{~kg} / \mathrm{m}^{3}$. The compressive strength of masonry was determined according to EN 1052-1 [29], by performing uniaxial compression tests on two series of $200 \mathrm{~mm}$ thick wallets with vertical (UCV) and horizontal (UCH) holes, respectively (Fig. 2). The tests were performed both on URM specimens and on masonry samples strengthened with SFRM coating. As shown in Table 2, the test specimens were identified with an ID in which the first two letters represent the type of test (UC $=$ Uniaxial Compression test), the second index denotes the orientation of unit holes $(\mathrm{V}=$ Vertical; $\mathrm{H}=$ Horizontal) and the third index is the specimen number. An additional index was used to represent masonry provided with coating on one $(\mathrm{R})$ or both side (RR) of the specimen. Note that the samples provided with a single layer of coating included only masonry with vertical holes.

As better explained in previous works [17, 18], the coating application technique consisted of the following main phases:

1. A first thin layer of mortar ( $\sim 5 \mathrm{~mm}$ thick) not containing steel fibers was applied by a trowel on the moistened surface of masonry.

2. Coating-to-masonry connectors (6 connectors for each strengthened surface), which consisted of a
$50 \mathrm{~mm}$ long nylon expansion plug and a steel screw with a diameter of $6 \mathrm{~mm}$ and a length of $60 \mathrm{~mm}$, were installed into masonry. Each screw was provided with a $50 \times 50 \times 1.8 \mathrm{~mm}^{3}$ steel anchor plate placed within the coating thickness (Fig. 2) at a distance of about $15 \mathrm{~mm}$ from the masonry surface. The plug was anchored only to the first shell of the clay block.

In real practice, a minimum of 6 connectors per square meter should be used, which corresponds to an average spacing of $400 \mathrm{~mm}$, as well studied in a previous paper [17]. The latter was adopted for the specimens UCH-RR. On the contrary, because of the smaller specimen size, a reduced spacing of $300 \mathrm{~mm}$ was used for the samples UCV-RR and UCV-R.

3. Different layers of SFRM were successively troweled on the masonry surface until the total required thickness $(25 \mathrm{~mm})$ was achieved.

4. To mitigate shrinkage cracking, water was sprayed on the specimen surface at least for 2 days after coating completion. The coating was applied after 7 days from the construction of the masonry wallet.

The adopted test set-up is shown in Fig. 2. Each specimen was placed on a layer of fresh mortar that allowed to level the contact surface between the base of the sample and the laboratory floor. Tests were carried out under displacement control by using an

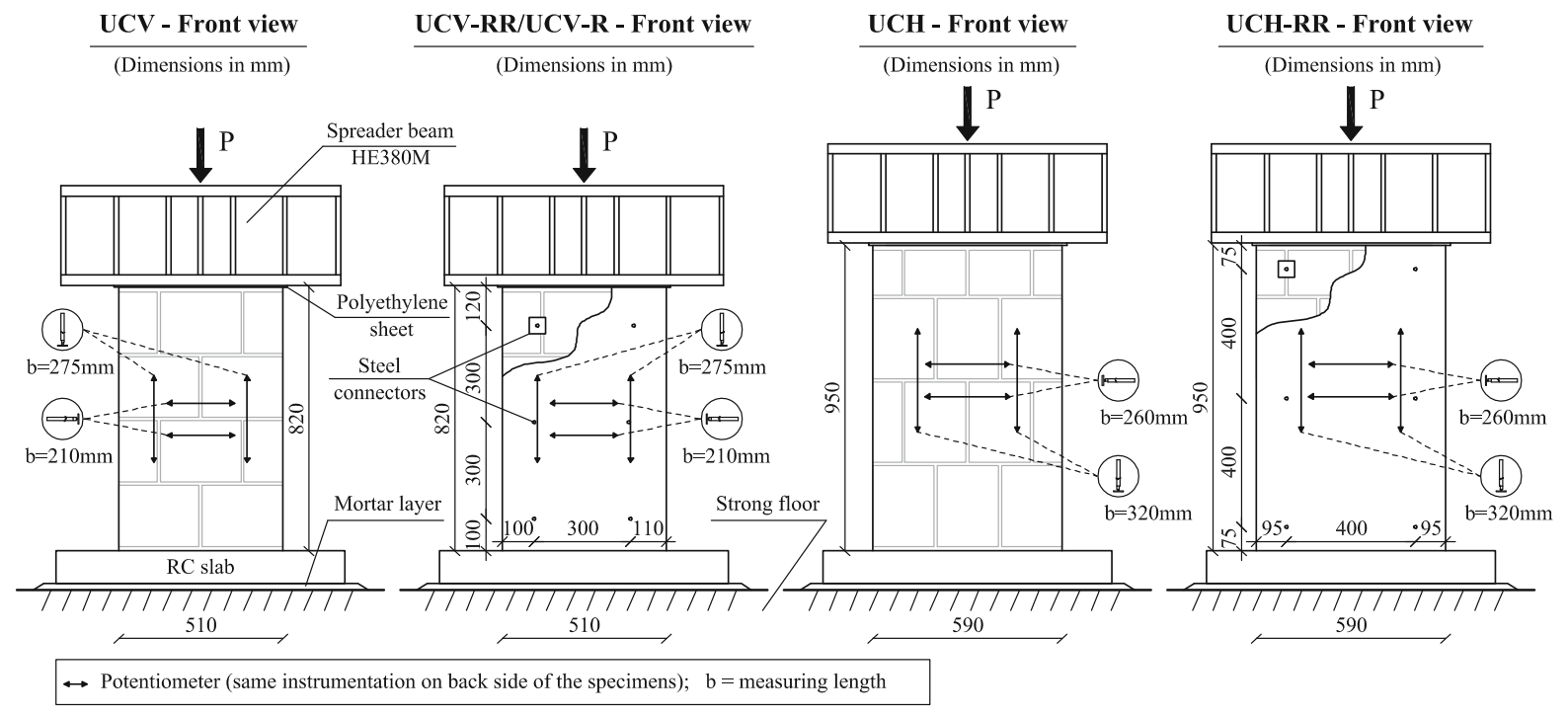

Fig. 2 Uniaxial compression test set-up 
Table 2 Main properties of the specimens and results of the uniaxial compression tests

\begin{tabular}{|c|c|c|c|c|c|}
\hline Specimen ID & Holes orientation & \# of coating layers & $\mathrm{E}_{\mathrm{m}}(\mathrm{MPa})$ & $\sigma_{\mathrm{v}, \max }(\mathrm{MPa})$ & $\varepsilon_{0}(\mathrm{~mm} / \mathrm{m})$ \\
\hline UCV1 & Vertical & - & 9462 & 3.69 & 0.81 \\
\hline UCV2 & Vertical & - & 11060 & 3.08 & 0.91 \\
\hline \multirow[t]{3}{*}{ UCV3 } & \multirow[t]{3}{*}{ Vertical } & - & 6413 & 2.02 & 0.83 \\
\hline & & Mean & 8978 & 2.93 & 0.85 \\
\hline & & $\mathrm{CoV}[\%]$ & 26.30 & 28.67 & 0.05 \\
\hline UCH1 & Horizontal & - & 1539 & 0.68 & 0.63 \\
\hline UCH2 & Horizontal & - & 1827 & 0.66 & 0.84 \\
\hline \multirow[t]{3}{*}{ UCH3 } & \multirow[t]{3}{*}{ Horizontal } & - & 1465 & 0.44 & 0.74 \\
\hline & & Mean & 1610 & 0.59 & 0.73 \\
\hline & & $\mathrm{CoV}[\%]$ & 11.93 & 22.03 & 13.70 \\
\hline UCV1-RR & Vertical & 2 & 9011 & 4.88 & 0.63 \\
\hline UCV2-RR & Vertical & 2 & 13895 & 4.50 & 0.57 \\
\hline \multirow[t]{3}{*}{ UCV3-RR } & \multirow[t]{3}{*}{ Vertical } & 2 & 14306 & 5.08 & 0.64 \\
\hline & & Mean & 12404 & 4.82 & 0.61 \\
\hline & & $\mathrm{CoV}[\%]$ & 23.70 & 6.02 & 6.17 \\
\hline UCH1-RR & Horizontal & 2 & 6406 & 1.24 & 0.22 \\
\hline UCH2-RR & Horizontal & 2 & 5581 & 2.04 & 0.57 \\
\hline \multirow[t]{3}{*}{ UCH3-RR } & \multirow[t]{3}{*}{ Horizontal } & 2 & 6352 & 1.91 & 0.53 \\
\hline & & Mean & 6113 & 1.73 & 0.44 \\
\hline & & $\mathrm{CoV}[\%]$ & 7.61 & 24.86 & 43.18 \\
\hline UCV1-R & Vertical & 1 & 7759 & 3.92 & 0.79 \\
\hline UCV2-R & Vertical & 1 & 8618 & 2.61 & 0.61 \\
\hline \multirow[t]{3}{*}{ UCV3-R } & \multirow[t]{3}{*}{ Vertical } & 1 & 7393 & 4.89 & 0.93 \\
\hline & & Mean & 7923 & 3.81 & 0.77 \\
\hline & & $\mathrm{CoV}[\%]$ & 7.90 & 30.18 & 20.8 \\
\hline
\end{tabular}

electromechanical jack having a capacity of $1000 \mathrm{kN}$. The point load $(\mathrm{P})$ was transferred to the top of the specimen by a steel beam HE380M, conveniently wider than the specimen thickness. Both the top and the bottom side of the specimen were provided with a polyethylene sheet that allowed to reduce masonry confinement due to friction.

Unlike EN 1052-1 [29] provisions, which does not consider the use of half height units, the first course of the specimens UCH was made with half blocks. This construction detail was adopted so that the samples $\mathrm{UCH}$ and UCV had the same slenderness (i.e., heightto-width ratio $=1.6$ ).

Before testing each wallet, the actual dimensions of the horizontal cross section were accurately measured to define the center of rigidity where the load $(\mathrm{P})$ had to be applied to prevent flexural mechanisms.

Tests were performed by monotonically increasing the vertical load up to the specimen failure. The deformations were detected by four potentiometric transducers placed on each side of the samples (eight in total, see Fig. 2). All specimens were cured in ambient condition for a minimum of 28 days from their completion.

\subsection{Results and discussion}

Figure 3 shows the vertical stress $\left(\sigma_{\mathrm{v}}\right)$ - strain $\left(\varepsilon_{\mathrm{v}}\right)$ response obtained from the compression tests. Moreover, Table 2 reports the main results including the initial (secant) elastic modulus $\left(\mathrm{E}_{\mathrm{m}}\right)$, the peak compressive stress (i.e. compressive strength $\sigma_{\mathrm{v} \text {,max }}$ ) and corresponding strain $\left(\varepsilon_{0}\right)$. The secant modulus was calculated from the origin to the point of the stressstrain curve corresponding to $1 / 3$ of the peak stress. The vertical stress was calculated as the ratio between the applied axial load and the gross area of wallet cross section. The area of coating was added to that of 


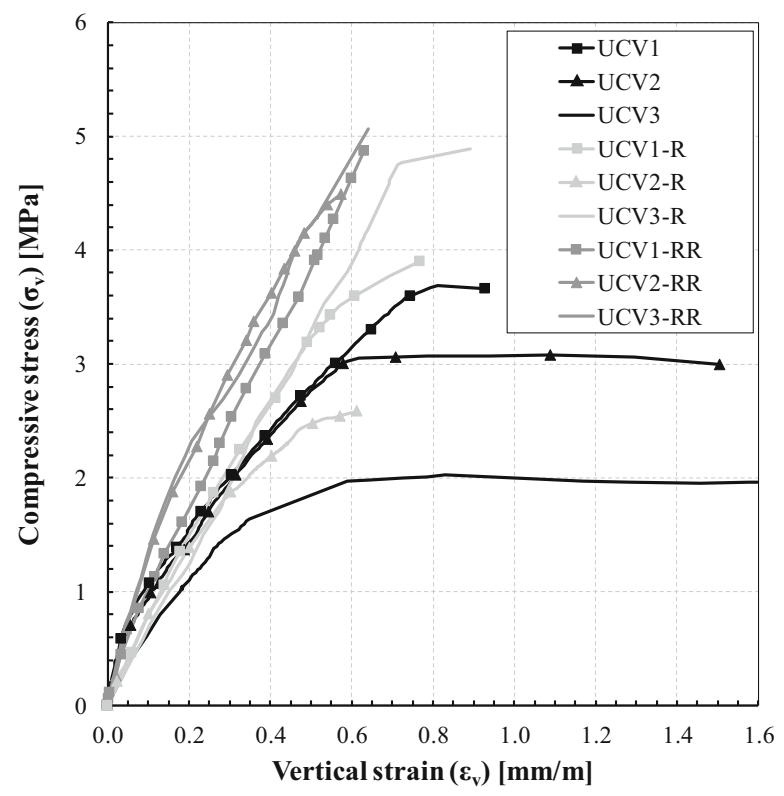

(a)

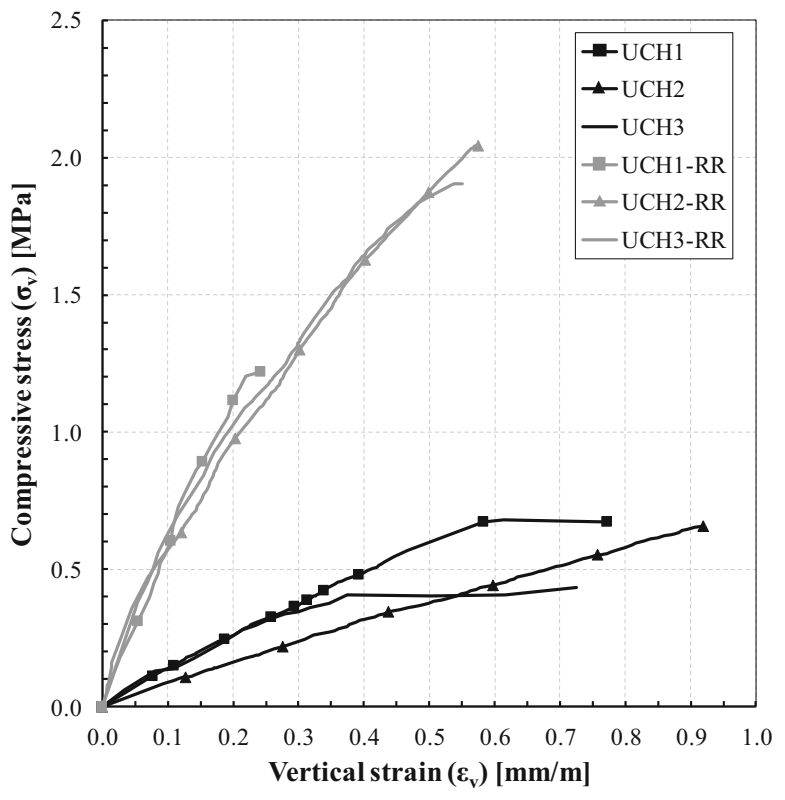

(b)

Fig. 3 Compressive stress-strain response of the samples with vertical (a) and horizontal holes (b)

masonry without performing any material homogenization.

According to the test results, the un-strengthened samples exhibited typical compression failure modes characterized by splitting cracks on the short side of the specimen (see Fig. 4a), sometimes in conjunction with crushing of the unit course placed in the upper half of the specimen (see Fig. 4d). Figure 3 shows that the first branch of the specimens' response was approximately linear except for a slight loss of stiffness due to vertical small cracks grown in the units before attaining the peak strength. Once the vertical deformation at peak $\left(\varepsilon_{0}\right)$ was reached, the load suddenly decreased as a result of splitting or crushing of units with brittle failure of the specimens.

Likewise the un-strengthened specimens, the strengthened wallets with vertical holes failed because of vertical splitting of units (Fig. $4 b-c$ ). On the contrary, the failure mechanism of the strengthened samples with horizontal holes was mainly governed by crushing of the unit course located at the top of the specimen (Fig. 4e). The detachment of SFRM coating from the masonry surface was generally not observed (Fig. 4c), proving the good bond strength that characterized the mortar-to-coating interface. Moreover, steel connectors concurred in preventing the detachment of coating when compression stresses caused significant damages to the external shell of clay blocks.

The response of the specimens strengthened on both sides clearly highlighted the ability of the proposed retrofitting technique to improve the compressive behavior of masonry. In fact, as compared to the reference specimens, the strength and the secant stiffness enhancement of the samples with vertical holes were equal to $65 \%$ and $38 \%$, respectively. Even more significant was the improvement exhibited by the samples with horizontal holes, which presented a mean compressive strength and an elastic modulus respectively $193 \%$ and $280 \%$ higher than the corresponding reference samples ones.

As expected, the application of a single layer of coating (only in the case of unit with vertical holes) resulted in $30 \%$ improvement of the average compressive strength. On the contrary, the elastic modulus presented a reduction approximately equal to $12 \%$. The latter can be explained by considering the asymmetry of the reinforcement, which caused outof-plane bending especially after the formation of cracks on the bare side of the specimen. After testing single-sided strengthened elements under diagonal compression, other authors $[10,30]$ came to the same 


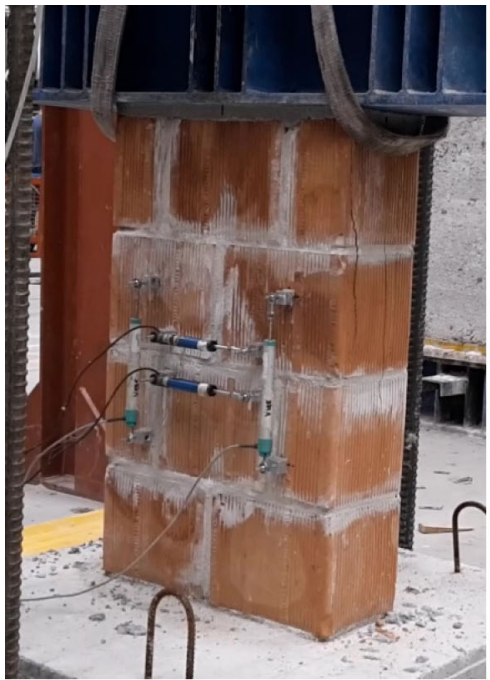

(a) UCV3

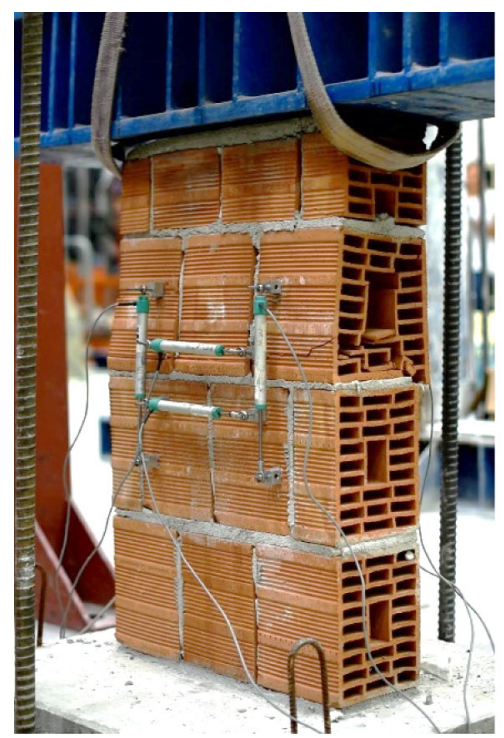

(d) $\mathrm{UCH} 3$

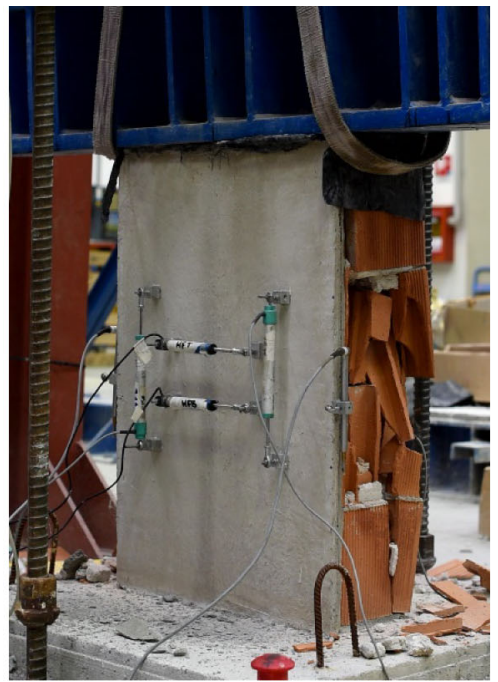

(b) UCV1-R

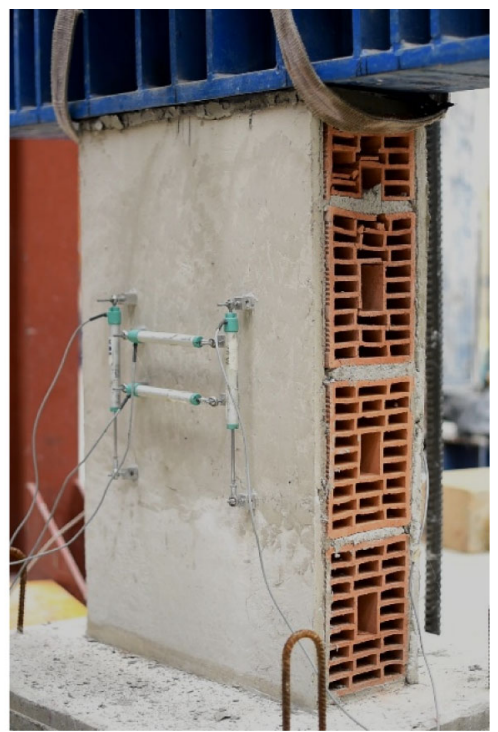

(e) UCH2-RR

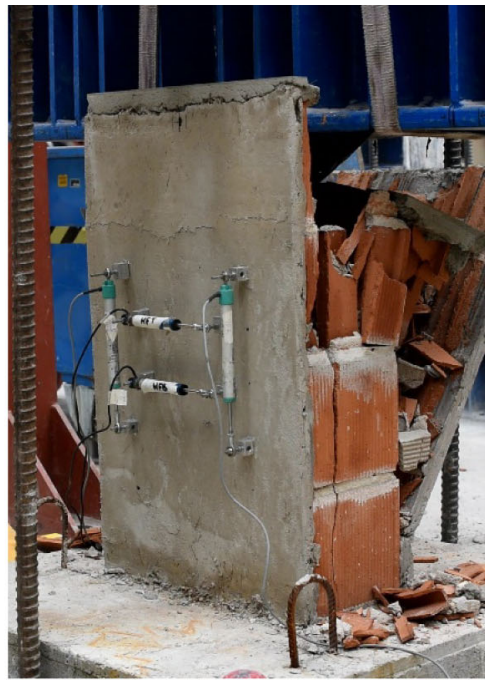

(c) UCV1-RR

Fig. 4 Ultimate crack patterns of the uniaxial compression tests

conclusion even if, according to their experimental observations, the specimen asymmetry had a detrimental effect both on the stiffness and on the capacity of the specimen.

As highlighted by Modena et al. [31], the significant increment of the axial stiffness may cause a variation of both the seismic response of the single structural elements and the distribution of lateral forces acting on the bearing walls of the building. Therefore, when performing the retrofitting intervention, typically
SFRM coating should be uniformly applied on all the bearing walls in order to prevent un-uniform distributions of the in-plane stiffness able to cause detrimental effects on the global seismic response of the building.

The elastic modulus of the strengthened wallets can be estimated by starting from the elastic moduli of the single material components, i.e. URM masonry and SFRM. Based on the traditional Bernoulli's principle (i.e., equal axial strains at the various points across a 
section), the elastic modulus $\left(\mathrm{E}_{\mathrm{m}, \mathrm{anl}}\right)$ results from the equilibrium as follows:

$$
\begin{aligned}
& \mathrm{E}_{\mathrm{m}, \mathrm{anl}}=\frac{\mathrm{E}_{\mathrm{m}} \cdot \mathrm{t}_{\mathrm{URM}}+\mathrm{n}_{1} \cdot \mathrm{E}_{\text {coat }} \cdot \mathrm{t}_{\text {coat }}}{\mathrm{t}_{\mathrm{URM}}+\mathrm{n}_{1} \cdot \mathrm{t}_{\mathrm{coat}}} \\
& =\left\{\begin{array}{c}
11268 \mathrm{MPa} \text { Specimen } U C V-R R, \mathrm{E}_{\mathrm{m}}=8978 \mathrm{MPa} \\
5375 \mathrm{MPa} \text { Specimen } U C H-R R, \mathrm{E}_{\mathrm{m}}=1610 \mathrm{MPa} \\
10250 \mathrm{MPa} \text { Specimen } U C V-R, \mathrm{E}_{\mathrm{m}}=8978 \mathrm{MPa}
\end{array}\right.
\end{aligned}
$$

where $\mathrm{E}_{\text {coat }}=20430 \mathrm{MPa}$ is the mean elastic modulus of SFRM (see Sect. 3); $t_{\text {URM }}=200 \mathrm{~mm}$ is the thickness of the URM wallet; $\mathrm{t}_{\text {coat }}=25 \mathrm{~mm}$ is the thickness of a single coating layer; $n_{1}=1,2$ is the total numbers of coating layers. According to the Eq. 1, the predicted values of the elastic moduli of the specimens UCV-RR $\left(\mathrm{E}_{\mathrm{m}, \mathrm{anl}}=11,268 \mathrm{MPa}\right)$ and $\mathrm{UCH}-\mathrm{RR} \quad\left(\mathrm{E}_{\mathrm{m} \text {,anl- }}\right.$ $=5375 \mathrm{MPa}$ ) are quite accurate as they are respectively $9 \%$ and $14 \%$ lower than those (Table 2) provided by the experimental tests. A larger difference $(+29 \%)$ was observed for the single-sided strengthened specimen (UCV-R).

The results of the compression tests showed the inability of the adopted technique to provide hollow masonry with a ductile response after the attainment of the maximum compressive strength. Thus, the use of SFRM is recommended for retrofitting interventions requiring limited ductility levels such as those involving low-rise buildings. In that case, the adoption of a low ductility level leads to high lateral forces that can be withstood by the significant strength improvement obtained from retrofitting with SFRM coating.

A final consideration concerns the Poisson's coefficient $(v)$ resulting from the horizontal deformations detected at about $30-40 \%$ of the maximum resistance. The mean value of $v$ exhibited by the specimens UCV and $\mathrm{UCH}$ was equal to $0.06(\mathrm{CoV}=56 \%)$ and 0.04 $(\mathrm{CoV}=160 \%)$, respectively. About the strengthened samples, the horizontal deformations were always lower than the sensitivity $( \pm 0.05 \mathrm{~mm})$ of the potentiometers and, therefore, they were not reliable.

\section{Diagonal compression test}

\subsection{Test method}

The diagonal shear strength of masonry was determined according to ASTM E519-02 [32] by diagonal compression tests on 1200x1200 $\mathrm{mm}^{2}$ panels (Fig. 5). As shown in Table 3, the specimens are identified by an index code consisting of two letters, which represent the type of test $(\mathrm{DC}=$ Diagonal Compression test), followed by the specimen number. A third index (RR) is used to distinguish the double-sided strengthened samples from the bare panels. Six specimens were tested: three reference samples without coating (i.e. DC1, DC2, DC3) and three samples (i.e. DC1-RR25, DC2-RR25, DC3-RR25) reinforced with $25 \mathrm{~mm}$ thick SFRM coating applied on both sides.

The application of the SFRM coating was made by using the same procedure described at Sect. 4.1. Here, to prevent the delamination or buckling of coating, a total of nine coating-to-masonry steel connectors were installed on each side of the specimen, leading to the connector layout shown in Fig. 5.

The test panels were built with bed joints parallel to the laboratory floor in order to represent the typical construction conditions occurring in real cases. After at least 28 days from construction, the panel was clamped by an external rigid steel frame and then carefully rotated $45^{\circ}$ to be positioned on a steel loading shoe. The adopted test set-up is described in Fig. 5. The diagonal load (P) was applied and monotonically increased by an electromechanical jack having a capacity of $1000 \mathrm{kN}$. A top steel beam (2UPN400) distributed the applied force on the top loading shoe. A layer of M20 mortar was placed both on the bottom shoe and under the top shoe for correctly positioning and levelling the panel.

Similarly to ASTM E519-02 [32] test prescriptions, in order to prevent local splitting of hollow units placed in contact with the loading shoes, 150x150x10 $\mathrm{mm}^{3}$ confining steel plates were located on each side of the panel. As shown in Fig. 5, these plates were fixed together by a couple of steel screwclamps having a rail cross section of $35 \times 7 \mathrm{~mm}^{2}$.

Two different techniques were used to monitor the deformations of the panels. Six potentiometric transducers were placed on the back side of the sample and aligned parallel to the panel diagonals (Fig. 5). On the front side of the sample the displacements were measured by using the 2D Digital Image Correlation (DIC) technique [33]. A 46 Megapixel Nikon camera was used to record digital images of the whole specimen surface during the loading stage. The camera was mounted on a tripod with its axis perpendicular to the panel surface. The system captured pictures every 


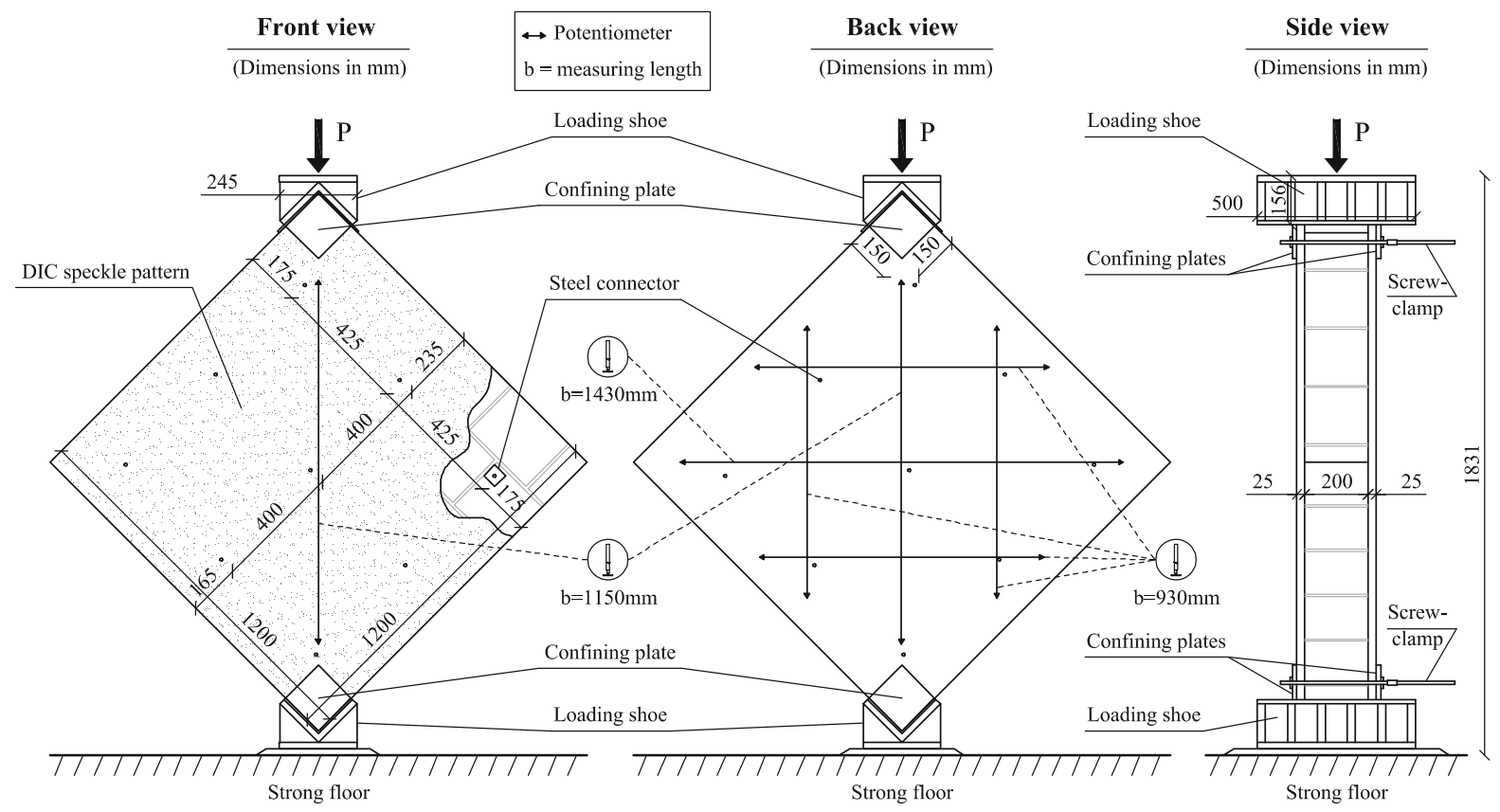

Fig. 5 Diagonal compression test: panel geometry and typical test set-up

$5 \mathrm{~s}$. The data analysis was performed by the commercial software Optecal ${ }^{\circledR}$ (www.optecal.com). Here, a subset size (i.e. the group of pixels that is compared in the loaded and reference pictures) of 45 pixels and a subset spacing of 13 pixels were adopted. To check the results provided by the DIC, a potentiometer was also aligned to the vertical diagonal of the panel. Before testing, the reference and the strengthened panels were cured at ambient conditions at least for 28 and 56 days respectively.

\subsection{Results and discussion}

Figutre 6 reports the shear stress $(\tau)$-strain $(\gamma)$ responses of the specimens. In addition, Table 3 reports the main results of the tests, including the maximum diagonal compression load $\left(\mathrm{P}_{\max }\right)$, the corresponding shear strength $\left(\tau_{\max }\right)$, the shear strain at the maximum load $\left(\gamma_{\max }\right)$, the shear modulus $(G)$ and the description of the failure mode. The ASTM provisions assume a uniform distribution of shear stresses in the panel. Thus: $\tau=\frac{0.707 \cdot \mathrm{P}}{\mathrm{A}_{\mathrm{n}}}$

where $A_{\mathrm{n}}$ is the net area of the specimen. The latter results from the following equation:

$A_{n}=\frac{b+h}{2} \cdot\left(t_{\mathrm{URM}} \cdot k+t_{\mathrm{coat}}\right)$

in which $b=h=1200 \mathrm{~mm}$ are the width and the height of the masonry panel, respectively; $k=0.4$ is the solid percentage of the gross area of the masonry unit. Note that the coating thickness term $\left(t_{\text {coat }}\right)$ must be neglected in case no coating is applied to the specimen. The shear strain $(\gamma)$ was calculated as.

$\gamma=\varepsilon_{V, \text { max }}+\varepsilon_{H, \text { max }}$

where $\varepsilon_{\mathrm{V} \text {,max }}$ and $\varepsilon_{\mathrm{H} \text {,max }}$ are respectively the vertical (shortening) and the horizontal (extension) strains measured along the panel diagonals.

Failure of all bare panels was governed by a classical combination of sliding-shear and diagonalshear mechanisms that caused a sudden drop of the 
Table 3 Masonry properties obtained from diagonal compression tests

\begin{tabular}{|c|c|c|c|c|c|c|c|c|c|c|c|c|c|}
\hline ID & $\begin{array}{l}\mathrm{P}_{\max } \\
(\mathrm{kN})\end{array}$ & $\begin{array}{l}\tau_{\max } \\
(\mathrm{MPa})\end{array}$ & $\begin{array}{l}\gamma_{\max } \\
(\mathrm{mm} / \\
\mathrm{m})\end{array}$ & $\begin{array}{l}\mathrm{G}_{0.015} \\
(\mathrm{MPa})\end{array}$ & $\begin{array}{l}\tau_{0.015} / \\
\tau_{\max } \\
(-)\end{array}$ & $\begin{array}{l}\Delta \mathrm{G}_{0.015} \\
(\%)\end{array}$ & $\begin{array}{l}\mathrm{G}_{0.05} \\
(\mathrm{MPa})\end{array}$ & $\begin{array}{l}\tau_{0.05} / \\
\tau_{\max } \\
(-)\end{array}$ & $\begin{array}{l}\Delta \mathrm{G}_{0.05} \\
(\%)\end{array}$ & $\begin{array}{l}\mathrm{G}_{0.1} \\
(\mathrm{MPa})\end{array}$ & $\begin{array}{l}\tau_{0.10} / \\
\tau_{\max } \\
(-)\end{array}$ & $\begin{array}{l}\Delta \mathrm{G}_{0.1} \\
(\%)\end{array}$ & $\begin{array}{l}\text { Failure } \\
\text { mode }\end{array}$ \\
\hline DC1 & 28.4 & 0.21 & 0.156 & 4000 & 0.29 & - & 2480 & 0.60 & - & 1720 & 0.84 & - & $\begin{array}{l}\text { Sliding- } \\
\text { shear } \\
\text { Diagonal- } \\
\text { shear }\end{array}$ \\
\hline DC & 44.3 & 0.33 & 0.354 & 6200 & 0.29 & - & 2600 & 0.40 & - & 1700 & 0.52 & - & $\begin{array}{l}\text { Sliding- } \\
\text { shear } \\
\text { Diagonal- } \\
\text { shear }\end{array}$ \\
\hline DC3 & 31.8 & 0.23 & 0.330 & 2867 & 0.19 & - & 2200 & 0.48 & - & 1600 & 0.69 & - & $\begin{array}{l}\text { Sliding- } \\
\text { shear } \\
\text { Diagonal- } \\
\text { shear }\end{array}$ \\
\hline Mean & 34.8 & 0.26 & 0.280 & 4356 & 0.26 & - & 2427 & 0.49 & - & 1673 & 0.68 & - & \\
\hline $\begin{array}{l}\mathrm{CoV} \\
{[\%]}\end{array}$ & 24.05 & 23.08 & 38.57 & 38.91 & 23.08 & - & 8.45 & 20.41 & - & 3.83 & 23.53 & & \\
\hline $\begin{array}{l}\text { DC1- } \\
\text { RR25 }\end{array}$ & 199.2 & 0.90 & 0.458 & 5333 & 0.09 & 22.4 & 3200 & 0.18 & 31.9 & 3200 & 0.36 & 91.3 & $\begin{array}{l}\text { Splitting } \\
\text { failure } \\
\text { Toe } \\
\text { crushing }\end{array}$ \\
\hline $\begin{array}{l}\text { DC2- } \\
\text { RR25 }\end{array}$ & 264.1 & 1.20 & 0.434 & 8133 & 0.10 & 86.7 & 4820 & 0.20 & 98.6 & 4100 & 0.34 & 145.1 & $\begin{array}{l}\text { Splitting } \\
\text { failure } \\
\text { Toe } \\
\text { crushing }\end{array}$ \\
\hline $\begin{array}{l}\text { DC3- } \\
\text { RR25 }\end{array}$ & 197.2 & 0.89 & 0.338 & 3267 & 0.055 & -25.0 & 3800 & 0.21 & 56.6 & 3600 & 0.40 & 115.2 & $\begin{array}{l}\text { Splitting } \\
\text { failure - } \\
\text { Toe } \\
\text { crushing }\end{array}$ \\
\hline Mean & 220.2 & 1.00 & 0.410 & 5578 & 0.08 & 28.0 & 3940 & 0.20 & 62.3 & 3633 & 0.37 & 117.2 & \\
\hline $\begin{array}{l}\mathrm{CoV} \\
(\%)\end{array}$ & 17.30 & 18.00 & 15.37 & 43.78 & 30.00 & 200.36 & 20.79 & 10.00 & 54.09 & 12.41 & 8.11 & 23.04 & \\
\hline
\end{tabular}

capacity right after the achievement of the peak load. As observed by other authors [11, 13], the three reference samples failed because of the formation of a diagonal stepped crack running along the bed and head joints. Only specimen DC3 showed a local crack involving two units in addition to cracking of mortar joints. The ultimate damage patterns of the bare panels are reported in Fig. 7a except for that of the specimen DC1, which suddenly failed and splitted in two parts right after the attainment of the maximum capacity.

As shown by the curves of Fig. 6 as well as by the results of Table 3, compared to the average maximum shear strength of the bare samples, the increasing in shear capacity of the strengthened panels ranged from a minimum of $242 \%$ (specimen DC3-RR25), to a maximum of $361 \%$ (specimen DC2-RR25). Figure $7 \mathrm{~b}$ shows the ultimate damage pattern of the specimen DC2-RR25, which is very similar to that of the other two strengthened panels. Despite the use of confining plates to prevent local damage of masonry, the SFRM coating remained almost totally un-cracked and the specimen failure was governed by splitting of the units located under the loading shoes. Few minor cracks were generally observed on the coating surface very close to the loaded corners. Thus, it appears that the traditional diagonal compression test set-up is not suitable for determining the diagonal tensile strength of double-sided strengthened panels tested in the 


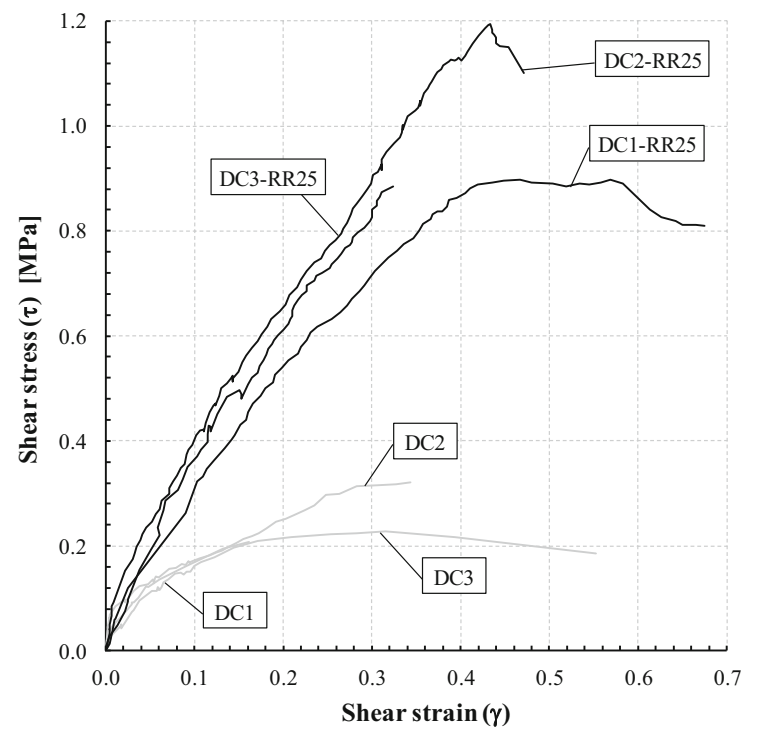

Fig. 6 Shear stress - strain response obtained from the diagonal compression tests

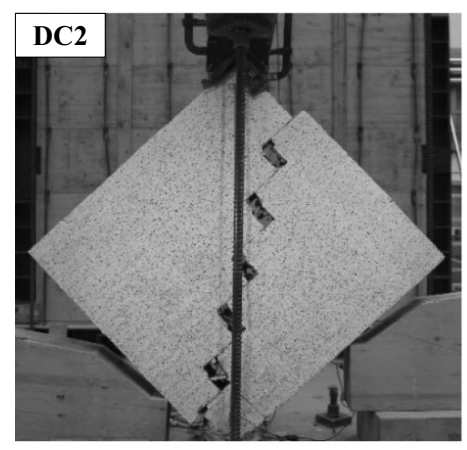

present research. However, the maximum shear strength achieved by those samples can be considered as a lower bound of the actual strength corresponding to diagonal cracking of SFRM coating.

The low ductility exhibited by the strengthened panels was mainly due to the premature splitting mechanism that prevented the formation of a diagonal shear crack in the coating layer. To assess the actual ability of coating to affect the ductility of the shear response, the diagonal test set-up should be redesigned including an axial compression force able to promote the shear failure of the panel.

As regard to existing unreinforced hollow block masonry, the Italian building code [3, 34] (clause C8.5.3.1-Table C8.5.I) reports values of the shear strength at zero normal stress $\left(\tau_{0}\right)$ ranging from $0.08 \mathrm{MPa}$ to $0.17 \mathrm{MPa}$, which correspond to tensile strength values $\left(\mathrm{f}_{\mathrm{tm}}=1.5 \cdot \tau_{0}\right)$ respectively equal to $0.12 \mathrm{MPa}$ and 0.26 MPa. Based on both the Frocht's

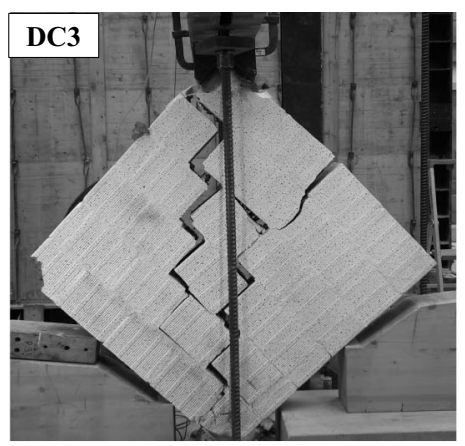

(a)

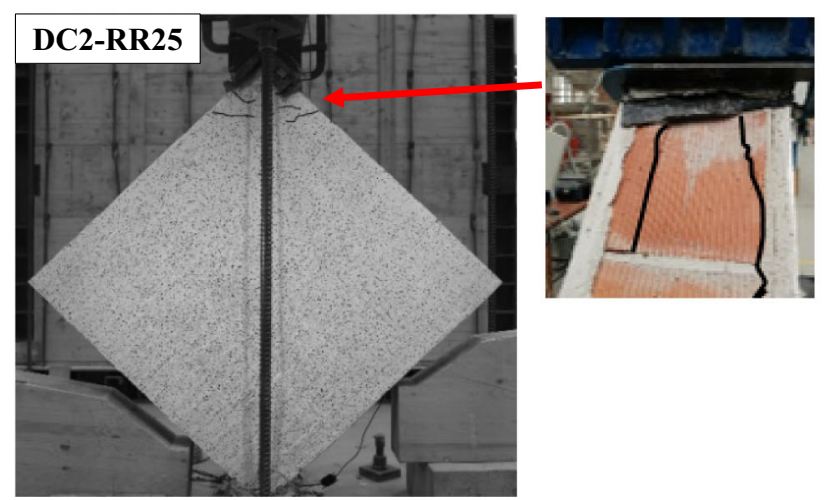

(b)

Fig. 7 Experimental damage pattern at failure and numerical contour of principal tensile strains detected at the maximum load: (a) reference and (b) strengthened panels 
theoretical solution [35] and the results of the numerical study carried out by Brignola et al. [36], the principal tensile stresses acting in the middle of the panel can be reasonably estimated as $0.7336 \cdot \tau$, where $\tau$ is the shear stress calculated according to Eq. (2). By means of the Frocht's solution, the tensile strengths reported by the Italian code can be turned into the corresponding tangential stresses, i.e. $0.16 \mathrm{MPa}=$ $0.12 \mathrm{MPa} / 0.7336$ and $0.35 \mathrm{MPa}=0.26 \mathrm{MPa} /$ 0.7336 . These limit values are consistent with the maximum shear stresses $\left(\tau_{\max }=0.21 \mathrm{MPa}-\right.$ $0.33 \mathrm{MPa}$ ) exhibited by the bare panels tested in this research (Table 3), thus confirming the reliability of the reference strengths reported by the Italian code.

By comparing the maximum shear strengths of the retrofitted panels $\left(\tau_{\max }=0.89-1.2 \mathrm{MPa}\right)$ with the shear strength range $(\tau=0.16 \mathrm{MPa}-0.35 \mathrm{MPa})$ obtained from the Frocht's solution for bare panels, one may conclude that a strength increment ranging from $154 \%$ (increment: 2.5 ) to $650 \%$ (increment: 7.5 ) may be expected. The latter boundary values are both higher than the factor 1.3 recommended by the Italian code [34] (clause C8.5.3.1-Table 8.5.II) to estimate the increment of masonry resistance due to retrofitting with ferrocement.

To better compare the bare samples with the strengthened ones, Table 3 reports three different values of the shear modulus, i.e. $G_{0.015}, G_{0.05}$ and $G_{0.1}$, which were calculated as the ratio of the shear stress (i.e. $\left.\tau_{0.015}, \tau_{0.05}, \tau_{0.1}\right)$ to the corresponding shear strain at $0.015 \mathrm{~mm} / \mathrm{m}, 0.05 \mathrm{~mm} / \mathrm{m}$ and $0.1 \mathrm{~mm} / \mathrm{m}$, respectively. The obtained values of the shear stresses were also divided by the maximum shear stress achieved by each of the test specimens. To appreciate the variation of the shear modulus of the strengthened panels with respect to the mean stiffness of the bare samples, the percent variation $\Delta \mathrm{G}$ was also reported in Table 3. As expected, the results showed that the mean initial stiffness $\left(\mathrm{G}_{0.015}\right)$ of the strengthened samples was about $28 \%$ higher than that exhibited by the unstrengthened panels. By increasing the reference shear strain up to $0.1 \mathrm{~mm} / \mathrm{m}$, the shear modulus progressively increased up to a maximum average value of about $117 \%$.

\section{Numerical analysis of diagonal compression test}

A numerical study was carried out with the aim of corroborating the experimental results provided by the diagonal compression tests. In more detail, the simulation of the un-strengthened panel allowed to identify a reasonable value of the shear mechanical parameters of masonry (i.e., cohesion and friction coefficient of mortar joints), since specific tests (e.g., direct shear test) for their determination were not performed in the present research program. Moreover, the analysis of the strengthened specimens provided further information about the behavior of the samples and allowed to assess the reliability of the experimental results.

\subsection{Finite element modelling}

The behavior of unreinforced masonry is mainly affected by the mechanism occurring at the unit-tojoint interface. However, as shown by others [37, 38], the use of interface elements increases the complexity of the model because of the huge amount of time required for its construction and for running the analysis.

To reduce the model complexity, Gabor et al. [39] proposed a simplified approach that considers masonry as a regular inclusion of bricks perfectly bonded to a matrix made of mortar. The non-linear behavior of the brick-to-joint interface can be totally attributed to mortar, assuming that the low volume of joints compared to that of bricks cannot considerably affect the overall response of the masonry element.

The finite element method was used to simulate the diagonal compression tests. Eight node isoparametric brick elements were used to discretize all the masonry components (i.e. units and mortar joints). The resulting 3D model was implemented in the commercial finite element code Diana 10.1 [40]. The size of the elements was uniform (Fig. 8): the mortar joints were modelled by $10 \times 40 \times 40 \mathrm{~mm}^{3}$ brick elements wheareas coarser solid brick elements having dimensions of about $40 \times 40 \times 40 \mathrm{~mm}^{3}$ were adopted to simulate the hollow clay units. The mortar layers and 
the units were rigidly connected so that relative slip was disabled. The two steel loading plates were modelled with brick elements rigidly connected to the panel. To further simplify the model, the behavior of the brick-to-loading plate interface was not modelled. This assumption was supported by the results of preliminary analyses that showed the negligible effect of the frictional parameters governing the interface on the response of the panels. As occurred in the experimental tests, the loading plates were connected both to masonry and to the coating layers (Fig. 8b).

To simulate the behavior of the strengthened panels, the two coating layers were modelled with solid bricks rigidly connected (i.e., perfect bond condition) to the masonry surface (Fig. 8). As no failure mechanisms involving the masonry-to-coating interface were observed during the tests, modelling of the interface behavior was neglected. Four additional steel plates connected to the coating surface were used to simulate the behavior of the confining plates (see Fig. 5) applied on the external coating surface. Transversal constraints (direction Z) were located on the external surface of the confining plates in place of the screw-clamps used in the experimental tests.

\subsection{Constitutive laws}

To represent the constitutive behavior of the mortar joints, the Drucker-Prager's yield condition [41] was considered. The material constants (i.e., $\alpha$ and k) that govern the yield function can be directly related to the internal friction angle $(\phi)$ and the cohesion (c) that characterize the Mohr-Coulomb's yield surface generally adopted to represent the behavior of masonry joints [42]. Since the non-associative plasticity was assumed, a dilatancy angle $(\psi)$ was also considered to define the plastic potential surface. In order to limit the tensile strength of the joints, the Drucker-Prager criterion included a tension cut-off depending on the tensile bond strength $\left(\mathrm{f}_{\mathrm{tj}}\right)$ of the brick-to-joint interface. As direct shear tests on masonry joints were not performed in this research, the values of the friction angle and of the cohesion were assumed equal to those reported by Giarretton et al. [30], who carried out a series of triplet tests on samples consisting of hollowclay blocks and mortar very similar to those adopted herein. Preliminary sensitivity analyses showed that the angle of dilatancy mainly affects the maximum shear resistance of the panel; in more detail, a $50 \%$ reduction of $\psi$ led to a $4 \%$ reduction of the panel capacity. A similar contribution of the dilatancy to the shear resistance of masonry specimens was also observed by Andreotti et al. [43]. Here, the angle $\psi$ was assumed to be equal to $0.5 \phi$, which represents a compromise between the least conservative assumption $\psi=\phi$ (not suitable for simulating masonry joints) and the most conservative assumption, i.e. $\psi=0$ [44]. To better reflect the weaker behavior of head joints,
Fig. 8 Finite element model of the unstrengthened panel (a) and of the panel strengthened with SFRM coating (b)

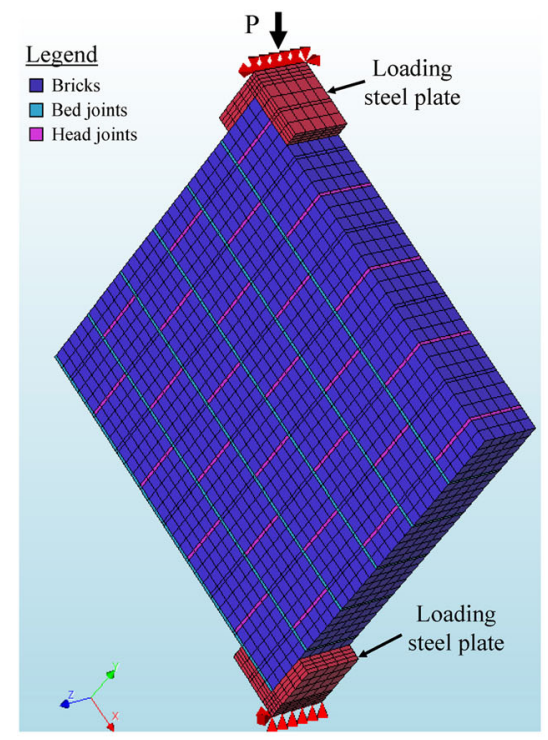

(a)

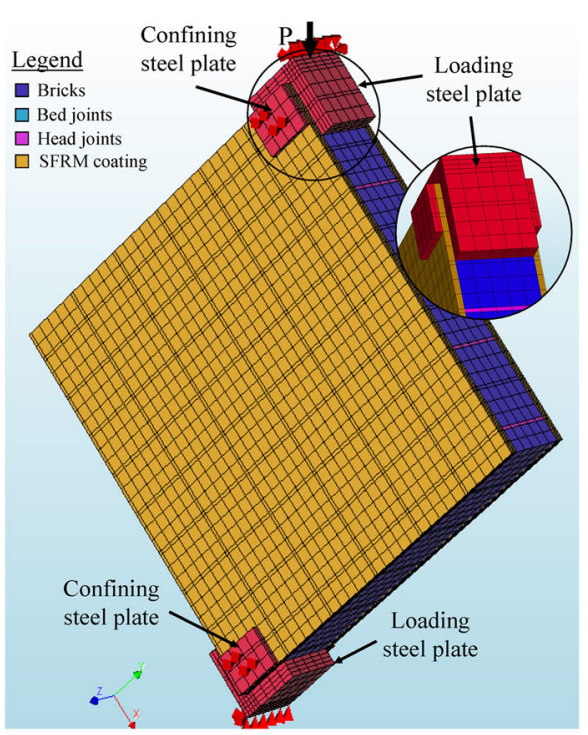

(b) 
the mechanical properties assigned to bed joints were significantly reduced. Finally, the elastic modulus of mortar $\left(\mathrm{E}_{\text {mor }}=6.2 \mathrm{GPa}\right)$ was assumed equal to the mean value obtained from the compression tests on cylinders discussed at Sect. 2.2 (Table 1).

The behavior of the masonry units and of the SFRM coating was represented by a rotating smeared-crack model [45] in which the axes of principal stress remain aligned with the principal strain directions even after cracking. Thus, the uniaxial constitutive laws representing the tensile and the compressive behavior of the material can be defined in terms of principal stress and strain. The compressive behavior was governed by the parabolic uniaxial stress-strain law proposed by Feenstra [46], which depends on the elastic modulus $(E)$, the compressive strength $\left(f_{c}\right)$, the strain at peak strength $\left(\varepsilon_{\mathrm{c}}\right)$ and the compressive fracture energy $\left(\mathrm{G}_{\mathrm{c}}\right)$. To ensure mesh objectivity [45], the latter was divided by the characteristic length $\left(\mathrm{h}_{\mathrm{el}}\right)$ of the single finite element [45], which is equal to the cube root of the brick element volume. The parameters adopted to define the compressive behavior are summarized in (Table 1).

Regarding the SFRM, the compressive strength and the elastic modulus were assumed equal to the corresponding values obtained from the material characterization tests (see Sect. 3), whereas the compressive fracture energy was estimated according to Nakamura and Higai (2001) [47] as 8.8. $\left(f_{c}\right)^{0.5}$ $\left(\mathrm{f}_{\mathrm{c}}=\right.$ mean compressive strength of SFRM).

About masonry units, the mean compressive strength measured normally to the brick holes (Table 1) was considered to determine the peak of the parabolic law, while the compressive fracture energy was calculated as $15+0.43 \mathrm{f}_{\mathrm{c}}-0.0036 \mathrm{f}_{\mathrm{c}}^{2}(\mathrm{~N} /$ $\mathrm{mm})$ according to Magenes et al. [48] $\left(\mathrm{f}_{\mathrm{c}}=\right.$ mean compressive strength of units perpendicular to perforations). As suggested by Gabor et al. (2005) [39], the elastic modulus of the masonry components can be calculated from the equilibrium of vertical stresses acting in a masonry prism subjected to uniaxial compressive loading. Therefore, once the elastic moduli of unreinforced masonry $\left(\mathrm{E}_{\mathrm{m}}=8978 \mathrm{MPa}\right)$ and mortar $\left(\mathrm{E}_{\mathrm{mor}}=6200 \mathrm{MPa}\right)$ were obtained from the characterization tests, the elastic modulus of the masonry units $\left(\mathrm{E}_{\mathrm{b}, \text { anl }}\right)$ was estimated as follows:

$E=E_{b, a n l}=\frac{\alpha \cdot E_{m}}{\alpha+1-E_{m} / E_{\mathrm{mor}}}=9195 \mathrm{MPa}$ with $\alpha=h_{b} / h_{\text {mor }}=19 ; h_{b}=190 \mathrm{~mm}$ is the nominal height of the masonry unit; $h_{j}=10 \mathrm{~mm}$ is the nominal thickness of mortar joints.

In order to take into account the influence of lateral confinement and transverse cracking on the compressive strength of both the masonry units and SFRM, the model proposed by Selby and Vecchio [49] and Vecchio and Collins [50] were used. Further details about the implementation of these models in multiaxial stress conditions can be found in [40].

According to Schubert [51], the tensile strength of masonry hollow units can be calculated as the $8 \%$ of their compressive strength, which was here assumed equal to that determined perpendicularly to the holes. A linear tensile stress-strain law was adopted to represent the tensile behavior of units before and after cracking. The elastic modulus $\mathrm{E}_{\mathrm{b} \text {,anl }}$ determined the slope of the first linear branch up to the attainment of the tensile strength $\left(\mathrm{f}_{\mathrm{t}}\right)$. The Mode-I fracture energy $\left(G_{f}^{I}\right)$, which was determined according to the experimental data reported by Van der Pluijm [52], governed the linear softening response after cracking. The tensile fracture energy was divided by the characteristic element size $\left(h_{\mathrm{el}}\right)$ to ensure mesh objectivity.

The tensile behavior of the SFRM was modelled by a multilinear relationship that was calibrated by the finite-element back analysis of the 3PBTs presented in Sect. 3 (see the "Back analysis" curve in Fig. 1). The finite element model of the test beam implemented in the code Diana 10.1 [40] consisted of a discrete crack represented by $2+2$ node linear interface elements, surrounded by linear elastic four-node isoparametric quadrilateral plane-stress elements. For the sake of brevity, further details about modeling are not here presented. The tensile stress $\left(\mathrm{f}_{1}\right)$ — crack width (w) law resulting from the calibration process is reported in Fig. 9. In the pre-cracking stage, the SFRM was assumed linear elastic ( $\mathrm{E}=$ elastic modulus of SFRM) up to first cracking, corresponding to the attainment of the uniaxial tensile strength $\left(f_{t}\right)$ (Fig. 9a). On the contrary, the tri-linear relationship of Fig. 9b was used to represent the behavior of SFRM after cracking. The mode-I fracture energy $\left(G_{f}^{I}\right)$ (i.e. the area subtended by the stress-crack width curve) was divided by the characteristic element length $\left(h_{\mathrm{el}}\right)$ to get the corresponding stress-strain relationship. 
Fig. 9 Uniaxial tensile law of SFRM: (a) pre-cracking stress $\left(f_{1}\right)$-strain $\left(\varepsilon_{1}\right)$ law; (b) post-cracking stress $\left(\mathrm{f}_{1}\right)$ crack width (w) law

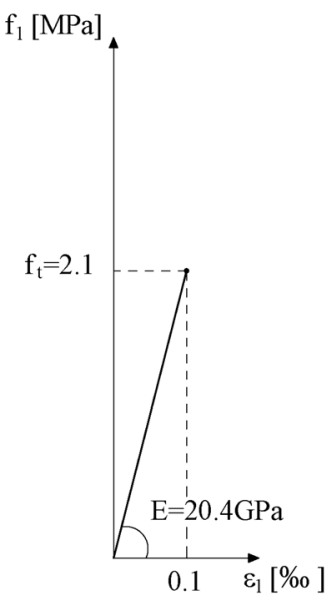

(a)

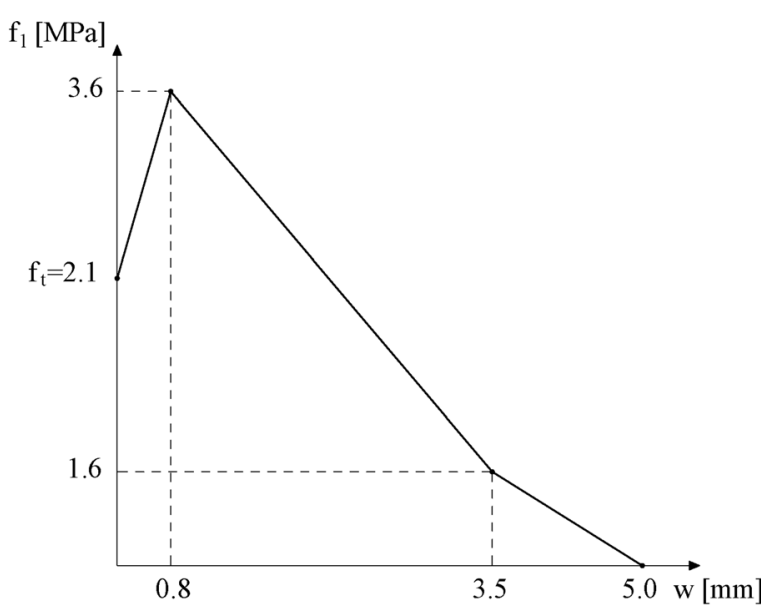

(b)

Table 4 Material parameters for finite-element modelling

\begin{tabular}{|c|c|c|c|c|c|c|c|c|c|c|c|c|c|}
\hline & \multicolumn{6}{|c|}{ Drucker-Prager plasticity model } & \multicolumn{7}{|c|}{ Smeared crack model } \\
\hline & $\begin{array}{l}\mathrm{E} \\
(\mathrm{GPa})\end{array}$ & $\begin{array}{l}v^{*} \\
(-)\end{array}$ & $\begin{array}{l}\mathrm{f}_{\mathrm{tj}} \\
(\mathrm{MPa})\end{array}$ & $\begin{array}{l}\mathrm{c} \\
(\mathrm{MPa})\end{array}$ & $\begin{array}{l}\phi \\
\left(^{\circ}\right)\end{array}$ & $\begin{array}{l}\psi \\
\left(^{\circ}\right)\end{array}$ & $\begin{array}{l}\mathrm{E} \\
(\mathrm{GPa})\end{array}$ & $\begin{array}{l}v^{*} \\
(-)\end{array}$ & $\begin{array}{l}\varepsilon_{\mathrm{c}} \\
(\% \mathrm{o})\end{array}$ & $\begin{array}{l}\mathrm{f}_{\mathrm{c}} \\
(\mathrm{MPa})\end{array}$ & $\begin{array}{l}\mathrm{f}_{\mathrm{t}} \\
(\mathrm{MPa})\end{array}$ & $\begin{array}{l}\mathrm{G}_{\mathrm{c}} \\
(\mathrm{N} / \mathrm{mm})\end{array}$ & $\begin{array}{l}\mathbf{G}_{\mathbf{f}}^{\mathbf{I}} \\
(\mathrm{N} / \mathrm{mm})\end{array}$ \\
\hline Bed joints & 6.2 & 0.2 & 0.05 & 0.09 & 14 & 7 & - & - & - & - & - & - & - \\
\hline Head joints & 6.2 & 0.2 & 0.01 & 0.01 & 7 & 3 & - & - & - & - & - & - & - \\
\hline $\begin{array}{l}\text { Masonry } \\
\text { units }\end{array}$ & - & - & - & - & - & - & 9.2 & 0.1 & 2.3 & 2.3 & 0.18 & 15 & 0.1 \\
\hline SFRM & - & - & - & - & - & - & 20.4 & 0.2 & 2.0 & 30.2 & 2.1 & 48 & 10.3 \\
\hline
\end{tabular}

$* v=$ Poisson's coefficient

The parameters implemented in the constitutive models presented above are summarized in Table 4 .

The numerical analysis was performed by using the Quasi-Newton (Secant) method with BFGS (Broyden-Fletcher-Goldfarb-Shanno) update. An imposed displacement applied to the top loading plate was monotonically increased until a significant reduction of the post-peak capacity was observed.

\subsection{Discussion of numerical results}

Figure 10 shows the comparison between the experimental and the numerical shear stress-strain responses of both the un-strengthened and the strengthened panels. The shear stress-strain response of the bare panel (DC-Num) is reported in Fig. 10a. The model parameters were calibrated so that the maximum capacity provided by the simulation (i.e.,
$0.28 \mathrm{MPa}$ ) was approximately equal to the average of the maximum and minimum strength obtained from the tests. The initial elastic branch of the numerical curve is similar to the experimental ones. Moreover, the numerical failure pattern (see Fig. 11a-contour of principal tensile plastic strains) appears to be consistent with the diagonal shear failure presented by the experiments. On the contrary, the model overestimated of about $100 \%$ the stiffness within the shear strain range $0.02-0.16 \mathrm{~mm} / \mathrm{m}$. This stiffness overestimation was mainly due to the high anisotropy of the hollow units, whose behavior was not well captured by the isotropic model adopted herein. The simulation of the orthotropic behavior of the units would require the implementation of either a more refined mesoscale modelling approach [e.g., 53] or a continuum nonlinear anisotropic model [e.g., 54] suitable for 3D analysis. Besides a higher computation cost, both 


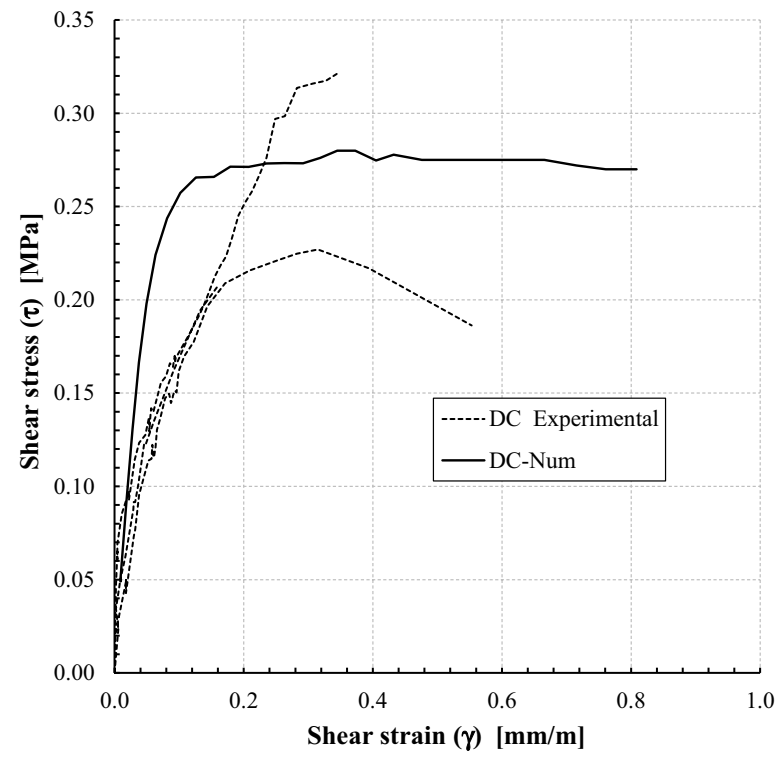

(a)

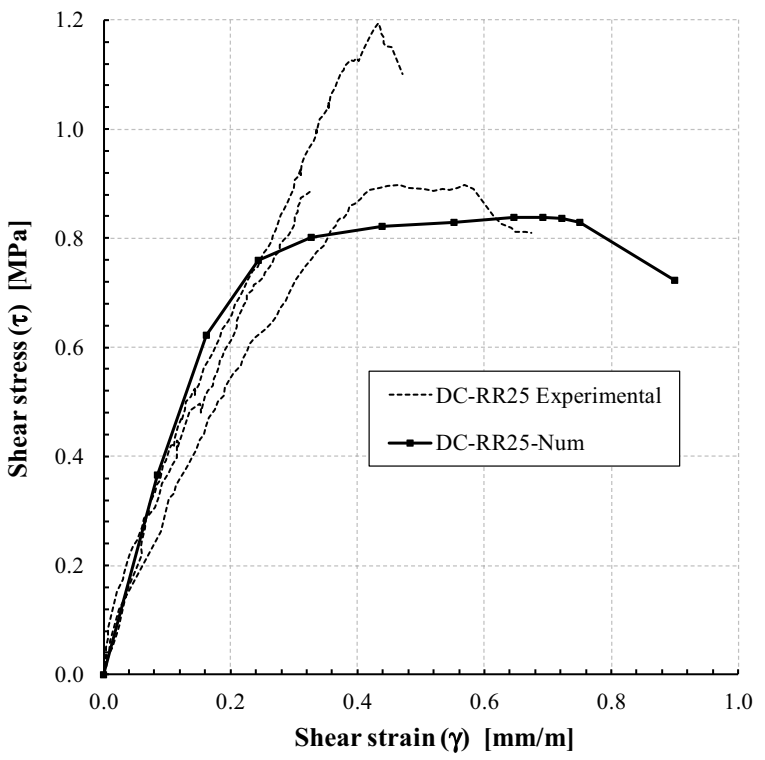

(b)

Fig. 10 Comparison between experimental and numerical shear stress-strain responses: (a) unstrengthened panels; (b) strengthened panels

Fig. 11 Contour of principal tensile strains at the maximum load resulting from numerical simulations of the diagonal compression tests: (a) reference panel; (b) panel strengthened on both sides

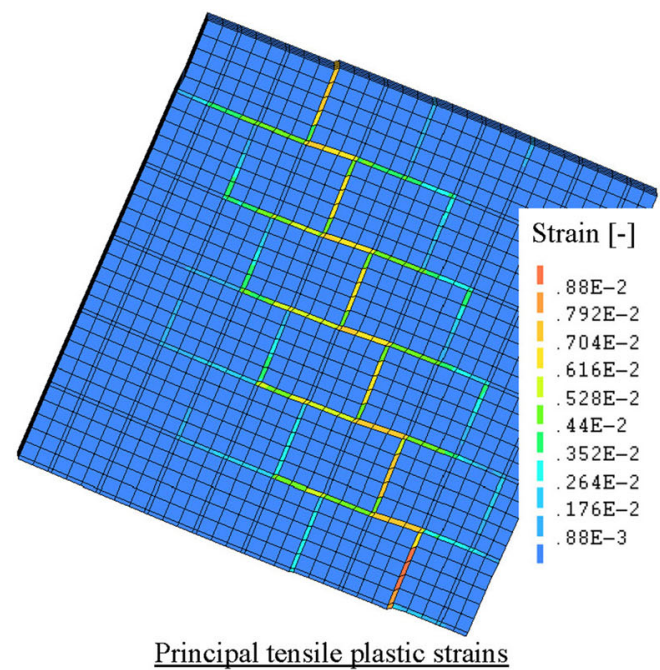

(a)

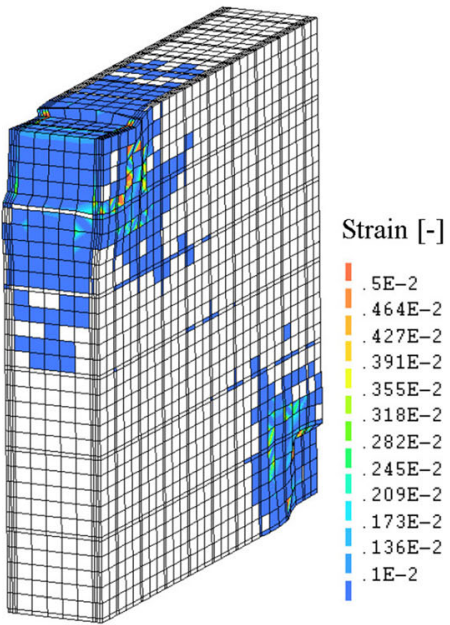

Principal tensile post-cracking strains

(b) options would require a model calibration process not supported by the mechanical properties currently available. Therefore, a non-linear isotropic model was chosen to the detriment of a poor prediction of the initial stiffness of the specimen. The latter did not significantly affect the ability of the finite element simulation to properly predict the panel response in terms of capacity and failure pattern.
The simulation of the strengthened panel (DCRR25-Num) resulted to be consistent with the experimental response both in term of global shear stressstrain response (Fig. 10b) and of failure mode (Fig. 11b). Compared to the unstrengthened panels, the initial stiffness was much more consistent with that exhibited by the test samples. To explain such a better response, one should consider that the pre-peak behavior of the panels was linear elastic because the 
high tensile strength of the SFRM prevented the formation of cracks both in the coating layers and in the masonry panel. The high elastic stiffness of the SFRM together with its isotropic behavior allowed to reduce the masonry anisotropy, particularly in the direction perpendicular to the block holes. The increased isotropy of the panel resulted in an improved ability of the numerical model to estimate the initial stiffness.

The numerical simulations confirmed that the ultimate behavior of the strengthened panels was governed by tensile cracking of masonry units located under the loading shoes. As observed in the tests, the analyses predicted the formation of some cracks on both the top and the bottom corner of the SFRM coating.

A final consideration concerns the scatter between the experimental and the numerical curves reported in the diagrams of Fig. 10. The variability of the masonry properties, which was however not considered in the simulations, probably affected the response of the panels leading to some inconsistencies between the experimental results. In each diagram, one of the three experimental curves appeared different compared to the others, which on the contrary were similar in terms of initial stiffness and capacity. Such a scatter of the experimental results affected the accuracy of the model calibration process. Further experimental tests must be done to improve the reliability of the model parameters.

The same model used to simulate the strengthened panels tested in this research was also adopted to perform an extension of the numerical simulations, in which different geometrical configurations of reinforcement were considered. The behavior of the double-sided strengthened panel was investigated by reducing the thickness of each coating layer to $15 \mathrm{~mm}$ (panel DC-RR15-Num), which represents the minimum feasible value for actual applications. Moreover, a single-sided strengthened panel was simulated by considering two different thicknesses of coating, i.e. $15 \mathrm{~mm}$ (panel DC-R15-Num) and $25 \mathrm{~mm}$ (panel DCR25-Num). The results of the simulations are shown in the diagram of Fig. 12a, which reports the shear stress against the shear strain obtained by averaging the values detected on the strengthened as well as on the bare side of the panel.

Because of the reduced $(-40 \%)$ thickness of coating, the maximum shear strength of the specimen
DC-RR15-Num resulted to be $40 \%$ lower than that exhibited by the panel DC-RR25-Num. Note that, in spite of the different thickness of coating, the two specimens were characterized by the same ultimate mechanism involving failure of the units located under the loading shoes.

A different behavior was predicted for the two single-sided strengthened panels, whose responses are represented by the grey curves in Fig. 12a. As one may observe, the curves presented a first linear branch followed by a second branch having a significantly lower slope. The change in slope is visible at a shear strain level of about $0.54 \mathrm{~mm} / \mathrm{m}(\tau=0.53 \mathrm{MPa})$ both for the panel DC-R15-Num and for the panel DC-R25Num. The reduction of the shear modulus that caused the aforementioned change of the curve slope was primarily due to the damages occurred on the unstrengthened side, which involved tensile cracking of the units and shear-slip failure of mortar joints. The latter mechanisms are highlighted by the contour of the principal tensile strains detected for the panel DCR15-Num (Fig. 12b). As observed by others [10, 14], the difference in stiffness on the opposite sides of the panel led to a clear bending deformation along the horizontal diagonal which, in turn, promoted the significant damage observed on the bare side. By increasing the shear deformation, cracks eventually propagated toward the strengthened side causing the progressive formation of a tensile crack along the vertical diagonal of the SFRM coating. These damaging phenomena did not cause the sudden collapse of the specimen as the high post-cracking strength of SFRM allowed to improve both the shear strength and ductility with respect to the specimen DC-RR15-Num. Note that the higher deformation capacity exhibited by the panels DC-R25-Num and DC-R15-Num with respect to the specimen DC-RR15-Num was probably not realistic as the out-of-plane bending mechanism promoted by single-sided strengthening led to an improved in-plane ductility. Both single-sided strengthened panels collapsed once the tensile crack completely localized along the vertical diagonal of the panel and crushing of coating and masonry units occurred at the top and bottom corners.

The potential effectiveness of the single-side reinforcement is proved by the comparison between the bare panel (DC-Num) and the specimens DC-R15Num and DC-R25-Num, whose maximum shear strengths were respectively $117 \%$ and $150 \%$ higher. 
Fig. 12 a Shear stressstrain response obtained from the parametric study. b Contour of principal tensile strains and deformed shape exhibited by the panel DC-R15-Num at different shear strain levels

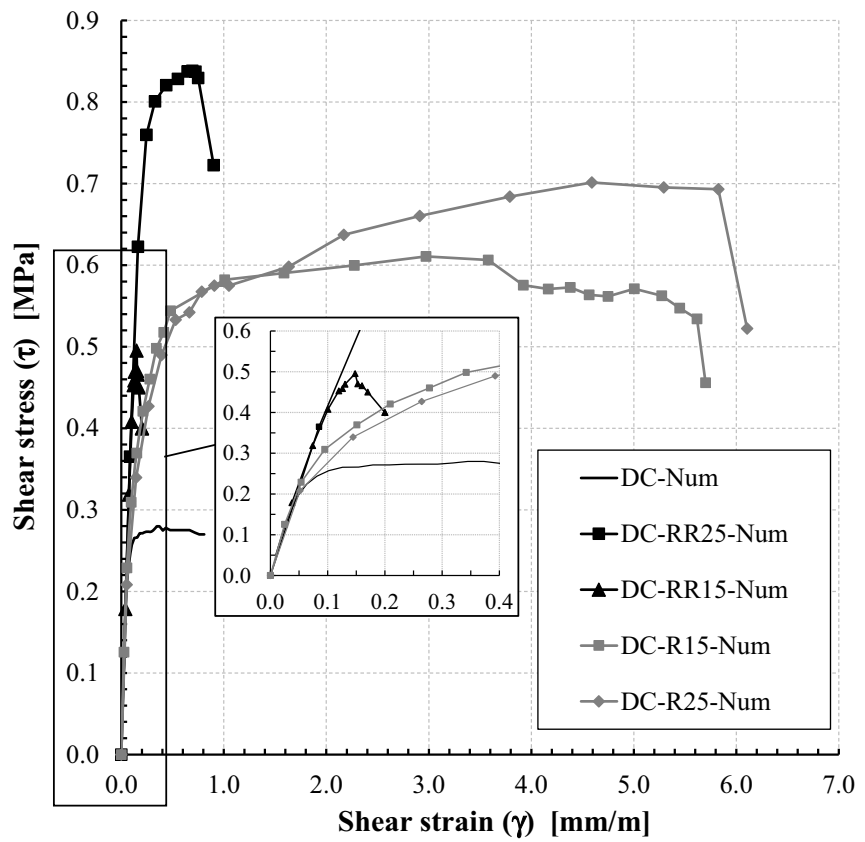

(a)

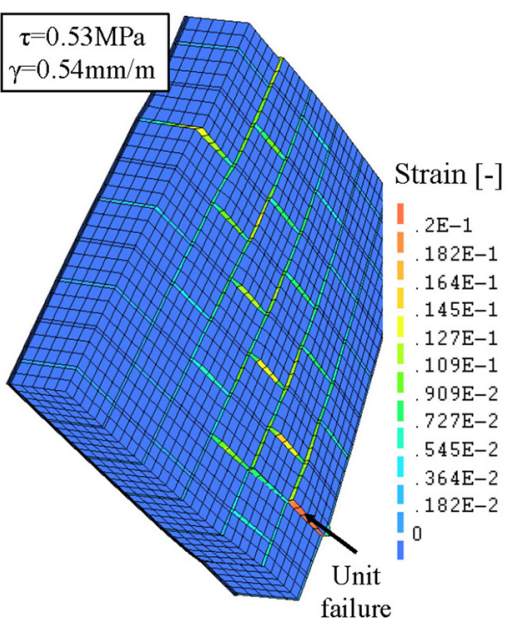

Bare side

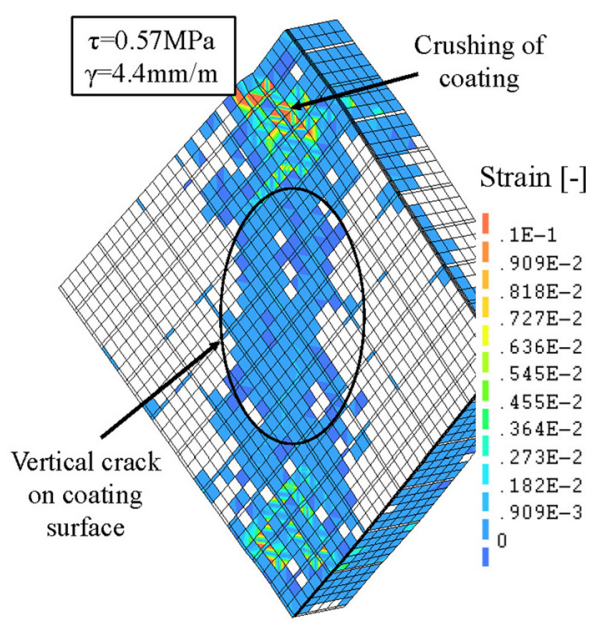

Strengthened side at failure

(b)

The results of this numerical study highlighted the potential ability of the proposed technique to improve the in-plane shear behavior of masonry. In actual applications, the improvement of the in-plane performance of brick and block masonry can be achieved provided that additional retrofitting interventions are adopted to prevent mode-I failure mechanisms and to improve the spread of horizontal forces amongst bearing walls. To this purpose, proper devices have to be installed to ensure an effective wall-to-wall and wall-to-floor connection. The latter are of utmost importance to reduce the structural effects related to the geometrical asymmetry of single-sided strengthening. 


\section{Conclusions}

In this paper, a comprehensive set of material tests was carried out and critical discussed to investigate the potential of using a thin SFRM coating for the strengthening of existing URM wall or buildings. Based on the results herein described, the following main conclusions can be drawn:

- The SFRM strengthening material presented good post-cracking tensile properties that make it suitable for improving the shear resistance of URM. The mode-I fracture energy of the SFRM $\left(G_{f}^{I}=10.3 \mathrm{~N} / \mathrm{mm}\right)$ is rather high as compared with typical values $\left(G_{f}^{I}=3-6 \mathrm{~N} / \mathrm{mm}\right)$ exhibited by normal strength concrete containing a similar amount of steel fibers.

- Free-shrinkage tests on SFRM prisms provided a total strain of about $600 \mu$ strain at 90 days. This value is quite lower as compared with long-term total shrinkage strain values (1000-2000 $\mu$ strain) typically exhibited by cement-based mortars used for repairing interventions.

- The application of a $25 \mathrm{~mm}$ thick coating on both sides of masonry provided an improvement of both the compressive strength and the elastic stiffness. The average compressive strengths of masonry with vertical and horizontal holes were respectively $65 \%$ and $193 \%$ higher than those achieved by the corresponding reference samples. The same tests showed increments of the average elastic moduli ranging from $38 \%$ (vertical holes) to $280 \%$ (horizontal holes). In spite of the significant improvement of the compressive behavior, the SFRM coating did not increase deformation capacity of masonry that generally exhibited brittle failure modes. It is worth remarking that the coating-to-masonry interface did not exhibit failure mechanisms. However, the masonry-to-coating connectors provided a significant confining effect as they prevented the detachment of the external shell of clay blocks from masonry once damages due to high compression stresses occurred.

- Compared to the bare samples with vertical holes, the single-sided strengthened specimens presented a 30\% increment of the compressive strength.

- The diagonal compression tests performed on the double-sided strengthened panels were all affected by crushing of masonry units that anticipated the formation of a tension failure mechanism of the SFRM coating. The test results proved that the shear strength and the shear modulus can experience a minimum improvement of $242 \%$ and $30 \%$, respectively.

- The non-linear finite element simulation of the diagonal compression tests performed on the bare specimens provided a quite accurate simulation of the observed response. The shear friction angle $\left(14^{\circ}\right)$ and the cohesion (0.09 MPa) used to characterize the mortar joints allowed to get a reasonable fitting of the experimental response. However, additional simulations and experimental tests should be carried out to confirm such results.

- The simulation of the double-sided strengthened panel confirmed the results of the experimental tests and proved that failure cannot be governed by the diagonal tensile cracking of SFRM coating, even in case its thickness is reduced from $25 \mathrm{~mm}$ to $15 \mathrm{~mm}$. The high tensile strength of SFRM delayed cracking of coating so that compression failure of masonry was the governing mechanism.

- The numerical simulations also showed that, in case a single-sided strengthening configuration is adopted, the specimen experiences large cracks on the unstrengthened and smaller cracks on the coated side. The latter are associated with the outof-plane bending resulting from the asymmetrical reinforcement. The use of a single $15 \mathrm{~mm}$ thick layer of SFRM coating may improve the shear strength of about $117 \%$. Such an improvement can be increased to $150 \%$ in case a $25 \mathrm{~mm}$ thick layer is adopted.

Acknowledgements The authors would like to thank Delta Phoenix s.r.l. for the financial contribution to this research work. The authors thanks also Eng.s Silvia Martini, Roberto Vecchi, Samuele Bedussi, Stefano Toninelli and Jessica Paterlini for their contribution in performing the tests and processing data.

Funding Open access funding provided by Università degli Studi di Brescia within the CRUI-CARE Agreement..

\section{Compliance with ethical standards}

Conflict of interest The authors declare that they have no conflict of interest.

Open Access This article is licensed under a Creative Commons Attribution 4.0 International License, which permits use, sharing, adaptation, distribution and reproduction in any 
medium or format, as long as you give appropriate credit to the original author(s) and the source, provide a link to the Creative Commons licence, and indicate if changes were made. The images or other third party material in this article are included in the article's Creative Commons licence, unless indicated otherwise in a credit line to the material. If material is not included in the article's Creative Commons licence and your intended use is not permitted by statutory regulation or exceeds the permitted use, you will need to obtain permission directly from the copyright holder. To view a copy of this licence, visit http://creativecommons.org/licenses/by/4.0/.

\section{References}

1. D'Ayala D, Speranza E (2003) Definition of collapse mechanisms and seismic vulnerability of historic masonry buildings. Earthquake Spectra 19(3):479-509

2. Como M (2013) Statics of historic masonry constructions. Springer, Berlin, p 588

3. NTC 2018 (2018) Decreto del Ministro delle Infrastrutture e dei Trasporti del 17/01/2018. Aggiornamento delle "Norme Tecniche per le Costruzioni”. G.U. n. 42 del 20 febbraio 2018. (In Italian)

4. EN 1998-1:2004/A1:2013 Eurocode 8: Design of structures for earthquake resistance-Part 1: General rules, seismic actions and rules for buildings, European Committee for Standardization

5. FEMA 273 (1997) NEHRP Guidelines for the Seismic Rehabilitation of Buildings. Basic procedures manual applied technology council (ATC), Washington DC, USA

6. Kahn L (1984) Shotcrete retrofit for unreinforced brick masonry. In: 8th WCEE, San Francisco, California, USA, pp 583-590

7. Lin YW, Wotherspoon L, Scott A, Ingham JM (2014) Inplane strengthening of clay brick unreinforced masonry wallettes using ECC shotcrete. Eng Struct 66:57-65

8. Messali F, Metelli G, Plizzari G (2017) Experimental results on the retrofitting of hollow brick masonry walls with reinforced high performance mortar coatings. Constr Build Mater 141:619-630

9. Binda L, Modena C, Baronio G, Gelmi A (1994) Experimental qualification of injection admixtures used for repair and strengthening of stone masonry walls. In: 10th International Brick/Block Masonry Conference, vol 2, Calgary, Canada, pp 539-548

10. Valluzzi MR, Tinazzi D, Modena C (2002) Shear behavior of masonry panels strengthened by FRP laminates. Constr Build Mater 16(7):409-416

11. Hamid AA, El-Dakhakhni WW, Hakam ZHR, Elgaaly M (2005) Behavior of composite unreinforced masonry-fiberreinforced polymer wall assemblages under in-plane loading. ASCE J Compos Construct 9(1):73-83

12. Tomaževič M, Klemenc I, Weiss P (2009) Seismic upgrading of old masonry buildings by seismic isolation and CFRP laminates: a shaking-table study of reduced scale models. Bull Earthq Eng 7(1):293-321

13. Gattesco N, Boem I, Dudine A (2014) Diagonal compression tests on masonry walls strengthened with a GFRP mesh reinforced mortar coating. Bull Earthq Eng 13(6): 1703-1726

14. Parisi F, Iovinella I, Balsamo A, Augenti N, Prota A (2013) In-plane behaviour of tuff masonry strengthened with inorganic matrix-grid composites. Compos B Eng 45(1):1657-1666

15. Facconi L, Minelli F, Giuriani E (2018) Response of infilled $\mathrm{RC}$ frames retrofitted with a cementitious fiber-mesh reinforced coating in moderate seismicity areas. Constr Build Mater 160:574-587. https://doi.org/10.1016/j.conbuildmat. 2017.11.033

16. Sevil T, Baran M, Bilir T, Canbay E (2011) Use of steel fiber reinforced mortar for seismic strengthening. Construct Build Mater 25(2):892-899

17. Facconi L, Minelli F, Lucchini S, Plizzari G (2018) Experimental study of solid and hollow clay brick masonry walls retrofitted by steel fiber-reinforced mortar coating. J Earthq Eng. https://doi.org/10.1080/13632469.2018. 1442264

18. Lucchini S, Facconi L, Minelli F, Plizzari G (2018) Retrofitting a full-scale two-story hollow clay block masonry building by steel fiber reinforced mortar coating. In: Proceedings of the 3rd FRC international workshop fibre reinforced concrete: from design to structural applications, Desenzano, Lake Garda, Italy-June 28-30 (Extended Absrtact on pp. 114-115). ISBN: 978-88-89252-44-4

19. Fib Bulletin 65 (2012) Model Code 2010, Final Complete Draft", International Federation for Structural Concrete (fib)

20. EN 772-1:2011 + A1:2015, Methods of test for masonry units - Part 1: Determination of compressive strength

21. EN 998-2:2016 Specification for mortar for masonry-Part 2: Masonry mortar

22. EN 1015-11:1999/A1:2006 Methods of test for mortar for masonry-Part 11: Determination of flexural and compressive strength of hardened mortar

23. UNI EN 12390-13:2013 Testing hardened concrete-Part 13: Determination of secant modulus of elasticity in compression, Italian Organization for Standardization (in Italian)

24. UNI EN 14651:2007 Test method for metallic fibre concrete-Measuring the flexural tensile strength (limit of proportionality (LOP), residual)

25. Hillerborg A, Modeer M, Petersson PE (1976) Analysis of crack formation and crack growth in concrete by means of fracture mechanics and finite elements. Cem Concr Res 6:773-782

26. Barros AO, Sena Cruz J (2001) Fracture energy of steel fiber-reinforced concrete. Mech Compos Mater Struct $8(1): 29-45$

27. Michels J, Christen R, Waldmann D (2013) Experimental and numerical investigation on postcracking behavior of steel fiber reinforced concrete. Eng Fract Mech 98:326-349

28. UNI 11307:2008 Prova sul calcestruzzo indurito-Determinazione del ritiro. (in Italian)

29. EN 1052-1:2001 Methods of test for masonry - Part 1: Determination of compressive strength

30. Giaretton M, Dizhur D, Garbin E, Ingham JM, da Porto F (2018) In-plane strengthening of clay brick and block masonry walls using textile-reinforced mortar. J Compos Constr 22(5):04018028 
31. Modena C, Pineschi F, Valluzzi MR (2000) Valutazione della vulnerabilità sismica di alcune classi di strutture esistenti e sviluppo e valutazione di metodi di rinforzo, CNR-Gruppo Nazionale per la Difesa dai Terremoti, 89 p. (in Italian)

32. ASTM E519-02 (2002) Standard test method for diagonal tension (shear) in masonry assemblages. American Society for Testing and Materials, West Conshohocken

33. Desai N (2016) Small-Strain measurement in bridges using the digital image correlation (DIC) technique. In: Proceedings of SPIE 9805, Health Monitoring of Structural and Biological Systems, 980530, Las Vegas NV

34. Circolare n. 7 del 21 Gennaio (2019) "Istruzioni per l'applicazione dell' «Aggiornamento delle Norme tecniche per le costruzioni» di cui al DM 17 gennaio 2018”. C.S. LL. PP. (In Italian)

35. Frocht MM (1931) Recent advances in photoelasticity-and an investigation of the stress distribution in square blocks subjected to diagonal compression. Appl Mech Div 53(11):135-153

36. Brignola A, Frumento S, Lagomarsino S, Podestà S (2009) Identification of shear parameters of masonry panels through the in situ diagonal compression test. Int $\mathrm{J}$ Architect Heritage 3(1):52-73

37. Lotfi HR, Shing PB (1994) Interface model applied to fracture of masonry structures. J Struct Eng 120(1):63-80

38. Lourenço PB (1996) Computational strategies for masonry structures. Ph.D. thesis, Technical University Delft, Delft University Press, The Netherlands, ISBN 90-407-1221-2

39. Gabor A, Ferrier E, Jacquelin E, Hamelin P (2006) Analysis and modelling of the in-plane shear behaviour of hollow brick masonry panels. Constr Build Mater 20(5):308-321

40. Diana 10.1 (2016) User's manual. Delft, The Netherlands: TNO DIANA BV

41. Drucker DC, Prager W (1952) Soil mechanics and plastic analysis or limit design. Q Appl Math 10(2):157-165

42. Zucchini A, Lourenço PB (2007) Mechanics of masonry in compression: results from a homogenisation approach. Comput Struct 85(3-4):193-204. https://doi.org/10.1016/j. compstruc.2006.08.054

43. Andreotti G, Graziotti F, Magenes G (2018) Detailed micromodelling of the direct shear tests of brick masonry specimens: the role of dilatancy. Eng Struct 168:929-949
44. Van Zijl G (2004) Modelling masonry shear-compression: role of dilatancy angle. J Eng Mech 130:1289-1296

45. Rots JG (1988) Computational modelling of concrete fracture. Ph. D. thesis. Delft University of Technology

46. Feenstra PH (1993) Computational Aspects of Biaxial Stress in Plain and Reinforced Concrete. Ph.D. thesis, Delft University of Technology

47. Nakamura H, Takeshi H (2001) Compressive fracture energy and fracture zone length of concrete. Modeling of inelastic behavior of RC structures under seismic loads. Edited by Benson Shing and Tada-aki Tanabe. ASCE Publications, pp 471-487. ISBN 0-7844-0553-0

48. Magenes G, Morandi P, Penna A (2008) Test results on the behaviour of masonry under static cyclic in plane lateral loads. Tech. Rep. ESECMaSE work package 7, deliverable D7.1 c, Enhanced Safety Efficient Construction of Masonry Structures in Europe

49. Selby RG, Vecchio FJ (1993) Three-dimensional Constitutive Relations for Reinforced Concrete. Tech. Rep. 93-02, Univ. Toronto, dept. Civil Eng., Toronto, Canada

50. Vecchio FJ, Collins MP (1993) Compression response of cracked reinforced concrete. J Struct Eng, ASCE 119, 12, $3590-3610$

51. Schubert P (2010) Eigenschaftswerte von Mauerwerk, Mauersteinen, Mauermörtel und Putzen. In: Jäger W (ed) Mauerwerk-Kalender. Ernst \& Sohn, Berlin (in German)

52. Van der Pluijm R (1992) Material properties of masonry and its components under tension and shear. In: Proceedings of the 6th Canadian Masonry Symposium, Saskatoon, Canada, pp 675-686

53. Massart TJ (2003) Multi-scale modeling of damage in masonry structures. Ph.D. Thesis, Eindhoven University of Technology \& Universite Libre de Bruxelles

54. Rafsanjani SH, Lourenço PB, Peixinho N (2015) Implementation and validation of a strain rate dependent anisotropic continuum model for masonry. Int $\mathrm{J}$ Mech Sci 104:24-43

Publisher's Note Springer Nature remains neutral with regard to jurisdictional claims in published maps and institutional affiliations. 